\title{
IMPLANTACIÓN DE FALSAS MEMORIAS EN NIÑOS Y NIÑAS A TRAVÉS DE UNA ENTREVISTA SUGESTIVA
}

\author{
Trabajo de Grado
}

Acero Triviño Jorge Enrique

Niño Castro Ruth Rosalba

Gutiérrez de Piñeres Botero Carolina ${ }^{1}$

Oyuela Vargas Raúl ${ }^{2}$

Universidad Santo Tomás

Facultad de Psicología

Maestría en Psicología Jurídica

Bogotá - Mayo de 2014

${ }^{1}$ Directora de Trabajo de Grado

${ }^{2}$ Director Metodológico 
Implantación de falsas memorias en niños y niñas 2

\title{
Implantación de falsas memorias en niños y niñas a través de una entrevista sugestiva
}

\author{
Acero-Triviño Jorge Enrique, Niño-Castro Ruth Rosalba y Gutiérrez de Piñeres-Botero \\ Carolina
}

Resumen

El objetivo de la presente investigación fue determinar mediante la comparación de grupos, la implantación de falsas memorias en niños y niñas de 3, 4 y 5 años de edad, a partir de dos tipos de entrevistas, una con preguntas sugestivas y otra con preguntas no sugestivas. El diseño fue cuasi experimental de tres grupos con postest. Se diseñaron dos tipos de entrevistas (con y sin preguntas sugestivas, respectivamente), sometidas a validación de contenido por jueces expertos. Los participantes fueron 36 niños, distribuidos en tres grupos de edades $(3,4$ y 5 años), cada grupo se dividió para la aplicación de los dos tipos de entrevistas. El procedimiento se llevó a cabo en ocho pasos, entre los que se destacan la creación del instrumento, contacto con los tutores de los participantes, desarrollo de la actividad y aplicación de las entrevistas. Los resultados se obtuvieron a través de un análisis comparativo entre grupos mediante la prueba paramétrica Anova de dos factores. Se encontraron diferencias significativas entre los grupos de acuerdo a la edad y al tipo de entrevista aplicada. Los resultados indicaron que los niños de tres años presentaron una mayor sugestión en cada uno de los ítems de la entrevista con preguntas no sugestivas, por el contrario los niños de cinco años, tendieron a responder de forma correcta sin permitir ser sugestionados por las indicaciones del entrevistador.

Palabras clave: memoria (34177); memoria episódica (34177); falas memorias (34174).

\section{Implantation of false memories in children through a suggestive interview}

\begin{abstract}
The aim of this investigation was to determine by comparing groups, the implantation of false memories in children 3,4 and 5 years, from two types of interviews, one with suggestive questions and the other with no suggestive questions. The design was three groups with posttest (quasi-experimental). We designed two types of interviews (with and without suggestive questions, respectively), submitted to content validation by expert judges. Participants were 36 children, divided into three age groups (3, 4 and 5), each group was divided for the application of the two types of interviews. The procedure was carried out in eight steps, among which are the design of the instrument, contact to the guardians of participants, activity development and implementation of the interviews. The results were obtained by a comparative analysis between groups using the parametric test ANOVA of two factors. There were significant differences between the groups according to age and type of interview applied. The results indicated that three years old children old had an increased suggestion in each of the items in the suggestive interview, instead five years old children tended to respond correctly without allowing be suggested by the interviewer.
\end{abstract}

Key words: memory (34177); episodic memory (34177); false memories (34177). 


\section{Tabla de contenido}

Introducción ................................................................................................................................5

Fundamentación bibliográfica.................................................................................10

Objetivos .................................................................................................................................34

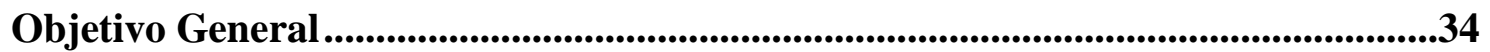

Objetivos Específicos.............................................................................................33

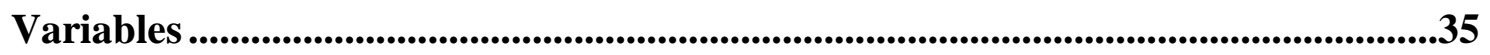

Variable dependiente: Falsa memoria...........................................................35

Variable independiente: Tipo de entrevista .....................................................35

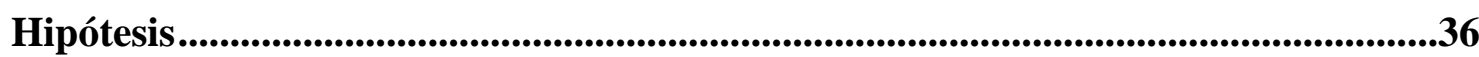

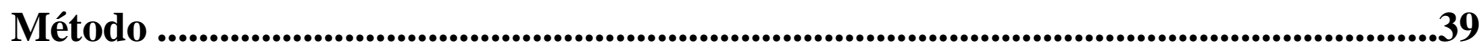

Tipo de investigación y diseño .......................................................................39

Participantes .....................................................................................................39

Instrumento.............................................................................................................41

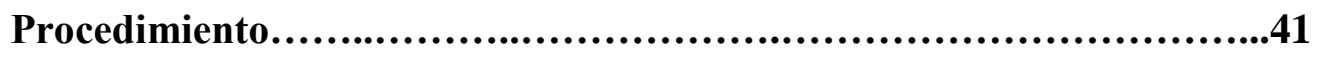

Análisis de datos.......................................................43

Aspectos éticos..........................................................43

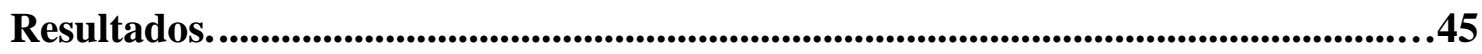

Validación por jueces expertos............................................................................45

Análisis de diferencias de medidas entre grupos ..............................................46

Análisis pregunta No. 10..............................................52

Análisis observaciones conductuales.....................................54

Discusión ................................................................................................................................57

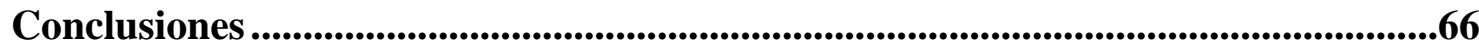

Referencias.......................................................................................................................70

Apéndice $\mathrm{A}$..................................................................................................................................75

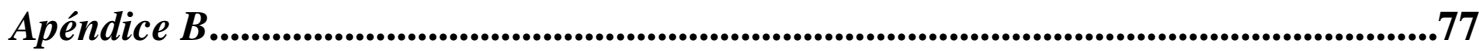

Apéndice C ......................................................................................................................79

Apéndice $D$.....................................................................................................................81

Apéndice $\mathrm{E}$..........................................................................................................................................82 


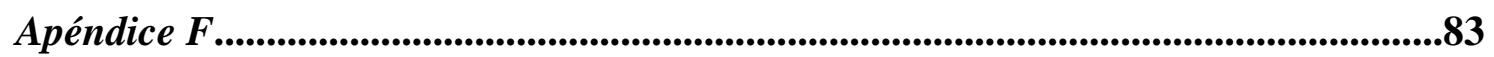

Apéndice $\mathrm{G}$...................................................................................................................................85

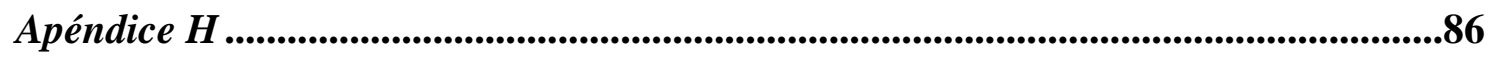

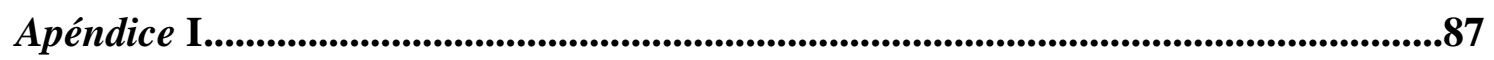

Apéndice $\mathrm{J}$..................................................................................................................88

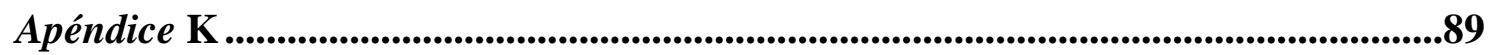

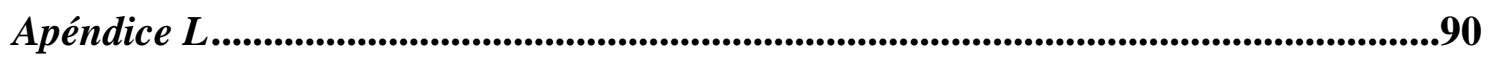

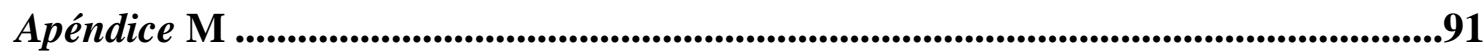

Apéndice $N$................................................................................................................92 


\section{Introducción}

La memoria de testigos, tanto en adultos como en niños, es un tema poco estudiado en nuestro país, en especial el tema de las Falsas Memorias (FM), entendidas estas como recordar hechos que no han ocurrido o recordarlos de forma diferente a como sucedieron (Payne, 1996, Roediger y MacDermott, 1996, citados por García-Bajos y Migueles, 1999). Por su parte Miramontes, Stein y Mojardín (2010) considera que las FM son reportes memorísticos que difieren parcial o totalmente de los eventos experimentados.

Para entender las FM, es importante conocer a profundidad el constructo memoria, identificándola como un sistema cognitivo que permite registrar, almacenar, elaborar y recuperar información vivida, que en algunas ocasiones se puede recordar con altos niveles de precisión y en otras ocasiones pueden llegar a ser recuerdos imprecisos (Mojardín-Heráldez, 2008). En este aspecto, Manzanero $(2008,2010)$ menciona que la mayoría de los adultos, son capaces de recordar hechos, como por ejemplo, el primer día de colegio, un viaje, un accidente, entre otros, pero siempre está la incógnita de si tales recuerdos son verdaderos. La mayor parte de los recuerdos infantiles son una reconstrucción realizada a partir de diferentes datos recogidos de distintas fuentes de forma no consciente, la reconstrucción de recuerdos autobiográficos se aleja de la realidad entre menor edad tiene la persona al momento de presentarse el suceso.

Cuando se presentan sucesos o situaciones vividas y su posterior remembranza existe la posibilidad de que los recuerdos sean reales y exactos en las características que hacen parte de ese recuerdo, pero al momento de recuperar recuerdos de situaciones vividas o simuladas que difieren parcial o totalmente de la realidad experimentada se denomina FM. Según MojardínHeráldez (2008), en ocasiones las FM se presentan como pequeñas desviaciones de forma, es decir, cambiar características de una situación vivida, por ejemplo, afirmar que un ladrón 
utilizaba un sombrero al momento de asaltar la tienda; pero en otras ocasiones se pueden presentar verdaderas modificaciones de los hechos vividos, como por ejemplo, reportar un abuso sexual que nunca tuvo lugar.

En cuanto a la clasificación de las FM Davies y Loftus (2006, citados por Manzanero, 2008) consideraron que existen tres tipos de FM: a) memorias selectivas o falsos selectivos en la información, b) memorias falsas sobre hechos que los sujetos no han vivido realmente, c) distorsiones o alteraciones de la memoria de hechos vividos por los sujetos. Así mismo, estos autores indican que, las posibles fuentes generadoras de estas FM son los procesos inferenciales y esquemáticos, y las fuentes de información sesgadas.

De acuerdo a Mojardín-Heráldez (2007) las FM se clasifican en dos, memorias implantadas y memorias espontáneas, la diferencia entre ellas se establece por el recurso que les da origen. La primera de ellas son reportes memorísticos creados por la influencia de información externa, por ejemplo un comentario equívoco de un tercero. Las memorias espontáneas son reportes memorísticos alterados por aspectos internos, propios del funcionamiento de la memoria, un ejemplo sería la inferencia.

El estudio de las FM en los últimos años ha sido un tema de interés por las múltiples implicaciones que pueden presentar en áreas como la legal, puesto que el análisis de los testimonios es fundamental para determinar la inocencia o culpabilidad de un procesado. En el área clínica, porque permitiría realizar intervenciones en las victimas que presentan las FM, brindando herramientas para recordar los hechos reales, así como estrategias de afrontamiento adecuadas. En el área educativa, ayudaría a mejorar las técnicas de enseñanza (Miramontes, Stein y Mojardín, 2010). 
Retomando las áreas en las cuales las FM tienen un papel importante, se encuentra la judicatura y en lo que respecta a los procesos judiciales los testimonios tienen un papel fundamental dentro de la investigación, siendo parte del cuadro de evidencias que puede llegar a encaminar o direccionar la toma de decisiones por parte de los jueces de Colombia. Es a través del testimonio que se incorporan, en el juicio oral del proceso penal, las pruebas directamente relacionadas a la víctima, victimario o testigos de un hecho delictivo, que van a ser valer las partes enfrentadas (defensa y fiscalía) en pro de sus intereses. En los demás procesos judiciales, ya sean civiles, laborales, contenciosos administrativos o de familia, el testimonio es una de las pruebas de mayor relevancia para los fallos que se deban proferir por parte de las autoridades judiciales.

En la psicología del testimonio, y de acuerdo con Garrido y Masip (2004), se han hecho observaciones a las entrevistas que se hacen a los niños y niñas dentro de un proceso judicial y, en algunos casos, se ha encontrado que los entrevistadores pueden llegar a hacer preguntas sugestivas, inductivas e incluso confusas y vagas, al igual que preguntas cerradas y dirigidas, lo que genera que la exactitud y credibilidad del testimonio sean cuestionadas en el proceso judicial.

De acuerdo con Garrido, Masip, y Herrero (2008), para establecer una serie de preguntas que permitan obtener la mayor cantidad de información fidedigna sobre el acontecimiento y con el cuidado de no sesgar u orientar en absoluto el recuerdo del entrevistado, se puede utilizar la entrevista paso a paso, con preguntas lo más abiertas posibles, para lograr de los niños y niñas una narración libre sobre los hechos de interés que se investigan y, a su vez, acercarse más a la exactitud y credibilidad de los relatos. 
Existen diferentes posiciones dentro de la comunidad legal y científica con respecto a las FM. Ibabe (2008) indica que desde hace algunos años existe un debate sobre las FM y memorias recobradas que ha polarizado dos comunidades, la académica y la de salud mental. Asimismo, para Butler y Spiegel (1997, Freyd, 1996, Knapp y VandeCreek, 2000, Pezdek y Banks, 1996, citados por Ibabe, 2008) bajo ciertas circunstancias pueden existir ambos tipos de memorias, falsas memorias y memorias genuinas recuperadas.

Por otro lado, se ha detectado un vacío en las investigaciones de implantación de FM en lo que respecta a la parte vivencial directa de los sujetos experimentales. En algunos casos los sujetos experimentales han sido expuestos a videos en los que se desarrolla una situación particular y dentro de la cual no fueron participes, por ejemplo un accidente de tránsito (Manzanero, 2002 y 2009), en otros casos, se les muestra una corta secuencia de videos de una película (Hernández y Roebers, 2007), e incluso se ha hecho uso de listas de palabras (Miramontes, Stein, Mojardín, 2010), en contraste, en el presente estudio los participantes vivenciaron directamente el evento.

En atención a que resultados de otros estudios han arrojado que las entrevistas que contienen preguntas sugestivas implantan falsas memorias a quienes son sometidos a ellas, esta investigación se orientó a identificar el efecto que tienen dos tipos de entrevistas (con preguntas sugestivas y con preguntas no sugestivas) sobre la memoria de niños y niñas entre los a 3 a 5 años de edad. Lo anterior, por cuanto las falsas memorias (falsos recuerdos), pueden repercutir en la exactitud del testimonio del niño, ya sea como víctima o testigo en un proceso judicial penal, civil, de familia o de cualquier otra índole.

Teniendo en cuenta las anteriores consideraciones, es importante y necesario que el medio judicial colombiano cuente con investigaciones que brinden soportes teóricos y empíricos con 
respecto a los testimonios y la influencia de la memoria y la implantación de falsos recuerdos en éstos, que permitan la argumentación científica en los juicios a favor de alguna de las partes, verificando o estableciendo la exactitud de los testimonios o la existencia de recuerdos influenciados por otras variables que puedan llevar a juzgar de forma errónea o injusta al acusado. De igual forma, los resultados de la presente investigación puedan servir de discusión empírica y marco de referencia en los debates o argumentaciones en el foro judicial colombiano como aporte para la psicología del testimonio. 


\section{Fundamentación bibliográfica}

Para comprender el contexto de la implantación de las FM en niños y niñas entre los tres y cinco años de edad que deben rendir testimonio en un juicio penal, civil o de familia, entre otros, como testigos o víctimas dentro de una investigación, y su posible repercusión en los procesos judiciales, a continuación se presenta una revisión de la literatura existente con respecto a la psicología jurídica, con énfasis en la psicología del testimonio y el papel que desempeña en el desarrollo de entrevistas o interrogatorios, en los que se busque evaluar de forma objetiva el testimonio de una persona acusada, de testigos o de victimas, sin incurrir en el error o la falta de sugerir o direccionar las respuestas, sesgando la investigación e incurriendo en el enorme error de culpabilizar a una persona, cuando no es responsable de los hechos que se investigan o absolviéndola en caso contrario.

La psicología, de acuerdo con la definición contemplada en la Ley 1090, (2006) por la cual se reglamenta el ejercicio de la profesión y se adopta su Código Deontológico y Bioético, es una ciencia sustentada en la investigación y una profesión que estudia los procesos de desarrollo cognoscitivo, emocional y social del ser humano, con la finalidad de propiciar el desarrollo del talento y las competencias humanas en los diferentes dominios y contextos sociales tales como: la educación, la salud, el trabajo, la justicia, la protección ambiental, el bienestar y la calidad de la vida. Entre tanto, Sinzer (1987, citado por Tapias y Hernández, 2011) considera que la psicología es la ciencia que describe, explica, predice y controla el comportamiento humano.

Con base en la investigación científica, la psicología fundamenta sus conocimientos y los aplica en forma válida, ética y responsable en favor de los individuos, los grupos y las organizaciones, en los distintos ámbitos de la vida individual y social, al aporte de 
conocimientos, técnicas y procedimientos para crear condiciones que contribuyan al bienestar de los individuos y al desarrollo de la comunidad, de los grupos y las organizaciones para una mejor calidad de vida.

La psicología como otros campos de estudio científico, se divide en ramas o áreas de estudio como la psicología clínica, psicología social, psicología organizacional, psicología jurídica, entre otras. En este aspecto, la psicología jurídica es el área de la psicología que desarrolla sus investigaciones y metodología para mejorar el ejercicio del derecho en general, y la intervención del sistema de justicia en particular, entendiéndose por éste fuerzas y cuerpos de seguridad, administración de justicia e instituciones penitenciarias (Muñoz, Manzanero, Alcázar, González, Pérez y Yela, 2011). De igual forma, para Tapias y Hernández (2011) la psicología jurídica es el área de la psicología que identifica su objeto de estudio en el comportamiento en ambientes jurídicos y con consecuencias jurídicas.

En igual sentido, un grupo de profesores de los posgrados en psicología jurídica de la Universidad Santo Tomás (2009, citados por Gutiérrez de Piñeres, 2010), define la psicología jurídica como "un área especializada, básica y aplicada de la psicología científica, que investiga e interviene sobre el comportamiento humano que alcanza implicaciones jurídicas, propendiendo por la defensa de los Derechos Humanos, la salud mental y el impacto de éstas en la sociedad, con el fin de alcanzar y humanizar la justicia" (p.230).

Por su parte, Muñoz, et al., (2011) proponen la agrupación de los distintos ámbitos que conforman la psicología jurídica en nueve áreas, así: a) psicología forense, pericial o psicología aplicada a los tribunales, b) psicología penitenciaria, c) psicología criminalística o psicología jurídica aplicada a la función policial, d) psicología jurídica aplicada a la resolución de conflictos, e) psicología del testimonio, f) psicología judicial, g) psicología de la victimización 
criminal, h) psicología criminal o psicología de la delincuencia \& i) psicología del trabajo y de las organizaciones aplicadas al sistema de justicia.

En lo que respecta a la psicología forense, pericial o psicología aplicada a los tribunales, se tiene que es una rama de la psicología jurídica que desarrolla sus conocimientos y aplicaciones con vistas a concluir sus hallazgos en el seno de una sala de justicia con la finalidad de auxiliar al juzgador en la toma de decisiones, (Soria, 2006, citado por Muñoz et al, 2011).

En lo relacionado con la psicología del testimonio, ésta es una subespecialidad de la psicología jurídica que denota su campo de aplicación dentro de la psicología forense, cuyo objeto de estudio es el testimonio y los factores que median en su exactitud, teniendo en consideración la forma como los procesos superiores, en especial la memoria, la percepción y la atención influyen en el mismo (Espinosa, 2011). En el mismo sentido y complemento, la psicología del testimonio como una rama de la psicología jurídica, tiene como propósito principal determinar hasta qué punto, lo que recuerda y reporta un testigo es exacto, o si por el contrario existen otras variables que han influido en su recuerdo.

Asimismo, para Querejeta (1999, citado por Luna y Migueles, 2007) la psicología del testimonio es la rama de la psicología que estudia los factores que determinan la calidad del testimonio de un testigo en un contexto judicial. En este sentido, según Muñoz et al (2011), indica que el testimonio como prueba o evidencia tanto como descripciones de situaciones o como identificación de perpetradores de un delito, es uno de los pilares probatorios en los distintos procesos judiciales, con mayor relevancia en los procesos penales. Los tópicos sobre los que ha basado la investigación dentro de la psicología del testimonio han sido cuatro (Manzanero, 2008, citado por Muñoz et al, 2011): 
1. Los factores de influencia en la exactitud de los testimonios, ya que éstos pueden ser imprecisos atendiendo a distintos factores que pueden incidir en el proceso de codificación, almacenamiento y recuperación del recuerdo;

2. Los procedimientos de obtención de declaraciones que permitan obtener la mayor cantidad posible de información exacta, sin influencias o sugerencias erróneas o negativas;

3. La evaluación de la credibilidad del testimonio, ya que constituye una demanda histórica por parte del derecho a la psicología la elaboración de métodos de detección de testimonios falsos (por engaño o error); y

4. Las pruebas de identificación realizadas por testigos y la evaluación de su exactitud, que ayudarían a evitar, o al menos minimizar, algunos de los errores que se cometen y a valorar adecuadamente la actuación de los testigos.

Para la psicología del testimonio es de vital importancia la memoria, porque todo lo que somos es memoria (Manzanero, 2008).

\section{Memoria}

La memoria es el sistema cognitivo que permite registrar, almacenar, elaborar y recuperar información vivida, que en algunas ocasiones se puede recordar con altos niveles de precisión y en otras pueden llegar a ser recuerdos imprecisos (Mojardín-Heráldez, 2008), en tanto Reed y Ellis (2007) consideran a la memoria como un proceso mediante el cual las experiencias pasadas influyen en el pensamiento y comportamientos presentes. Para Baddeley (1998), sin memoria, el hombre no sería capaz de percibir, aprender o pensar, no podría expresar sus ideas y no tendría identidad personal, porque sin recuerdos sería imposible saber quién es cada quién y la vida perdería sentido. 
El investigador Carrillo- Mora (2010), considera que es más correcto denominar la memoria en términos de sistemas de memoria, al considerar que ésta no es una función cerebral estática, única o aislada, sino que se comporta más como un conjunto de funciones distintas del cerebro pero estrechamente interrelacionadas que están orientadas hacia un mismo fin.

En este sentido, y para una mejor comprensión sobre la memoria, es necesario indicar que en las últimas décadas, diferentes investigadores han elaborado clasificaciones y teorías con respecto al proceso de la memoria, relacionándolo con diferentes sistemas, como por ejemplo el del modelo de un procesador. Entre las teorías vigentes y más aceptadas se encuentran las teorías del procesamiento de la información, en el que se asume que la memoria puede subdividirse en distintos procesos fundamentales.

\section{Etapas de la memoria.}

De acuerdo con Lahey (1999) y Gramunt-Fombuena (2008) el modelo del procesamiento de la información permite realizar un seguimiento a ésta, a medida que pasa a través de las siguientes operaciones: entrada, codificación, almacenamiento y recuperación o evocación.

1. Entrada: la información externa entra al sistema de memoria a través de los receptores sensoriales, la atención actúa en este nivel en la selección de información para un procesamiento subsiguiente.

2. Codificación: es el proceso inicial por el que la información física se transforma en una representación mental almacenada (Delis y Kramer, 2000, citado por GramuntFombuena, 2008), es decir, el proceso por el que las características de un estímulo o de un hecho son tratadas y convertidas en una huella mnésica. 
3. Almacenamiento: se refiere al mantenimiento de la información para poder acceder a ella cuando se requiera. Supone una transferencia de una memoria transitoria a una forma o ubicación cerebral para su retención permanente o posterior acceso.

4. Recuperación o Evocación: representa el proceso consciente de acceso a la información almacenada.

Para otros autores, la memoria como proceso tiene tres momentos o etapas, las cuales se han denominado codificación, entendida como un proceso en el que se transfiere una información al almacén de la memoria, en el que se involucra la percepción y la presentación de la información para que pueda ser manejada con posterioridad; almacenamiento, siendo este el banco de datos para ser utilizado posteriormente; y la recuperación que es cuando se utiliza la información almacenada en la memoria (Puente, 2005).

Otros autores han señalado que, dentro del proceso de la memoria, se encuentran la fase de adquisición, en la que el sujeto percibe el suceso y la información entra en el sistema de memoria; la fase de retención, que es el trascurso del tiempo antes que la persona intente recordar el suceso; y la fase de recuperación, cuando el sujeto intenta recordar la información almacenada (Loftus, Greene y Doyle, 1994, citados por Espinosa, 2011).

\section{Tipos de memoria.}

En 1890, William James propuso una de las primeras y más duraderas clasificaciones que caracterizan a la memoria: la memoria a corto plazo y la de largo plazo. Desde entonces se han propuesto las siguientes clasificaciones (Gramunt-Fombuena, 2008):

1. Memoria a Corto Plazo (MCP): el recuerdo de material es de forma inmediata posterior a su presentación. Se considera de limitada capacidad. 
2. Memoria a Largo Plazo (MLP): hace referencia al recuerdo de información tras un intervalo en el que la atención del sujeto se centra en aspectos distintos del objetivo. Se considera de gran capacidad.

3. Memoria Declarativa (MD): también conocida como memoria explícita, refiere a las memorias que son directamente accesibles de forma consciente; a menudo se ha empleado el término de forma genérica, abarcando entre estas memorias la episódica y la semántica.

4. Memoria No Declarativa (MND): denominada memoria implícita, se refiere a distintos sistemas de memoria, siendo los más estudiados el priming (la exposición previa a determinado material facilita el posterior rendimiento de un sujeto ante el recuerdo de ese mismo material) y el aprendizaje de habilidades o memoria procedimental.

5. Memoria Episódica (ME): se entiende como el recuerdo de sucesos específicos, que pueden ser asignados a un momento concreto en el tiempo. Permite la recolección personal consciente de acontecimientos y hechos del propio pasado (Tulving, 1972, citado por Pinchanski-Fachler, Víquez y Zeledón, 2004 y Gramunt-Fombuena, 2008).

6. Memoria Semántica (MS): se refiere al almacén general de información de datos; no está temporalmente codificada y alberga información que no depende de un tiempo o lugar determinado. En si representa el corpus de conocimiento e información compartido por los miembros de una misma sociedad.

Teniendo en cuenta lo anterior, existe una variada clasificación de la memoria, en una de ellas se encuentran la memoria implícita y la memoria explicita, cuya diferencia radica en las diferentes estructuras neurológicas en que están ubicadas y en la forma en que se procesa la información (Kolb y Whishaw, 2006). 
La memoria implícita, de acuerdo con Kolb y Whishaw (2006), en su mayor parte, se codifica en la misma forma en que se recibe, es decir, que el proceso es manejado de abajo hacia arriba, lo que la hace dependiente de la recepción de la información sensorial y no requiere de ninguna manipulación del contenido de la información por parte de los procesos corticales, es por esto que, la persona tiene un papel pasivo en el proceso de codificar este tipo de memoria, y puede tener dificultades para un recuerdo voluntario, pero recordará fácilmente cuando lo asocie a alguno de los rasgos del estímulo original.

La memoria explicita, depende de los procesos controlados conceptualmente o de arriba hacia abajo, en los cuales las personas reorganizan los datos para almacenarlos, teniendo un papel activo en el procesamiento de la información, los estímulos internos que utiliza en el procesamiento pueden ser usados para un recuerdo espontáneo (Kolb y Whishaw, 2006).

La memoria explicita, se subdivide según Tulving (1972, citado por Puente, 2005) en memoria episódica y memoria semántica. La memoria episódica consiste en los sucesos, hechos y acontecimientos que las personas recuerdan con respecto a sus vidas. Esta memoria es un sistema neurocognitivo, relativo al conocimiento, único y diferente de otros sistemas de memoria, que permite a las personas recordar las experiencias personales pasadas, es decir, "es la memoria de las experiencias vitales relativas a la propia persona” (Kolb y Whishaw, 2006, p. 458).

En cuanto a la memoria episódica, Redd y Ellis (2007) consideran que en ella se encuentra la memoria autobiográfica, la cual hace referencia a las experiencias personales de cada individuo. Tanto la memoria episódica como la autobiográfica abarcan experiencias de índole personal, diferenciándose en que los recuerdos autobiográficos son considerados por las personas como importantes y relevantes para su vida. 
Con el objeto de distinguir la memoria episódica de la semántica, Puente (2005) indica que en la memoria episódica son importantes las coordenadas de tiempo y lugar, mientras que en la memoria semántica no hace referencia a tiempos y lugares específicos. Pese a la anterior distinción, actualmente se acepta que su funcionamiento es interdependiente, toda vez que el conocimiento a nivel semántico se adquiere de las pequeñas experiencias personales vividas y experimentadas, por ejemplo, el conocimiento del uso de una silla se adquiere mediante las experiencias diarias con tal objeto, entonces, la manera como la persona procesa los rasgos de una silla en particular, está condicionada por el conocimiento semántico almacenado en la memoria (Puente, 2005).

No se puede tener memoria episódica sin tener previamente el conocimiento general y organizado que los seres humanos poseen del lenguaje y del mundo, esto es lo que hace que el funcionamiento de la memoria episódica y la memoria semántica sea interdependiente, por ejemplo un niño no podría recordar que desayunó el día de ayer (memoria episódica) sin que previamente conozca los conceptos de los alimentos que ingirió (memoria semántica).

Entre otras clasificaciones de la memoria, y que juega un papel importante para la persona que entrega testimonio de la vivencia de un evento, se encuentran la memoria icónica o visual y ecoica o auditiva. La primera es considerada como un almacenamiento que se produce en alguna de las fases del proceso de la percepción visual (Turvey, 1973, citado por Manzanero, 2008), que está compuesta por la retina que recibe imprecisiones luminosas y representa imágenes, determinando características de estímulos como la brillantez, intensidad y tiempo de exposición y su otro componente el cerebro que ejecuta el procesamiento central de la información enviada por el medio óptico (Puente, 2005); en tanto la memoria ecoica es un sistema de almacenamiento 
sensorial auditivo que posibilita el procesamiento de estímulos breves en cuanto a frecuencia y amplitud (Manzanero, 2008).

De las diversas fuentes revisadas, se observa que con relación a la memoria se han planteado diferentes clasificaciones o sistemas, en un principio desde los paradigmas empíricos y filosóficos más que científicos, hasta en la actualidad con diversas dicotomías como memoria declarativa y no declarativa, memoria consciente y memoria inconsciente, memoria de corto plazo y memoria de largo plazo, memoria implícita y memoria explicita, memoria retrospectiva y memoria prospectiva, recuerdo voluntario y recuerdo involuntario, así como memoria de trabajo, activa o diversas variedades de memoria como la explícita de largo plazo, dentro de ella la semántica, episódica y autobiográfica colectiva.

De acuerdo con lo que antecede, los sistemas de memoria mencionados son los más aceptados e investigados hasta el momento, sin embargo el estudio de clasificación de la memoria no ha finalizado aún, estando a la espera de nuevas investigaciones con sus correspondientes resultados.

\section{Diferencias entre recuerdo y reconocimiento.}

El recuerdo y el reconocimiento son dos procesos de la memoria diferentes. El recuerdo es un proceso activo de búsqueda para recuperar un aprendizaje adquirido, es decir, es el propio proceso de recuperar una representación de la memoria y presentarla ante la conciencia, y puede ser libre cuando se evocan los eventos en el orden que quiere el individuo o serial cuando el recuerdo debe hacerse según el orden de presentación de los eventos; en tanto el reconocimiento es el proceso orientado a la identificación de algo o alguien como familiar, verbigracia reconocer caras, nombres, identificar la alternativa correcta en un examen de selección múltiple, se observa 
que en este proceso hay ya algo en la experiencia inmediata para ayudar a la recuperación (Puente, 2005).

La diferencia entre reconocimiento y recuerdo, radica en que en el primero debe existir en la memoria algún tipo de representación permanente de "eso" que se experimentó con anterioridad y que de alguna forma se conecta con la experiencia presente, dando lugar a la sensación de reconocimiento, en cambio, en el recuerdo el algo o alguien familiar no está inicialmente presente en el pensamiento o la precepción consciente (Puente, 2005).

Para el autor en citado anteriormente, la diferencia entre recuerdo y reconocimiento radica en que en el reconocimiento debe existir en la memoria algún tipo de representación permanente de ese algo anteriormente experimentado que de alguna forma se conecta con la experiencia presente y tal contacto de lugar a la sensación de reconocimiento, en cambio, en el recuerdo el algo o alguien familiar no está inicialmente presente en el pensamiento o la precepción consciente.

En el proceso de tomar el testimonio o entrevistar a las personas involucradas en el hecho delictivo (victima, victimario y testigos), es importante poner atención a los recuerdos que las personas expresan sobre la situación vivida, permitiendo un relato libre, sin direccionar o sugerir hechos o nombres de personas con el fin de no implantar falsas memorias y generar un sesgo o falsas imputaciones en los juicios.

\section{Falsas memorias}

La memoria es sin duda un proceso cerebral notable, mediante el cual el sistema nervioso codifica, organiza y almacena los sucesos del pasado de forma que, en ocasiones, permite recordar consciente y vívidamente eventos distantes en el tiempo como si se experimentaran de nuevo (Carrillo-Mora, 2010). No obstante, en general la mayoría de los adultos son capaces de 
recordar hechos o situaciones vividas, como por ejemplo el primer día de colegio, un viaje, un accidente, entre otros, pero en ocasiones puede existir la incógnita de si tales recuerdos son verdaderos. De acuerdo con Manzanero (2008, 2010), la mayor parte de los recuerdos infantiles son una reconstrucción realizada a partir de diferentes datos recogidos de distintas fuentes de forma no consciente y dicha reconstrucción de recuerdos autobiográficos se aleja de la realidad entre menor edad tiene la persona al momento de presentarse el suceso.

Es importante mencionar, que la diferencia entre la memoria de los niños y la de los adultos, de acuerdo con Goodman, Rudy, Bottons y Aman (1990, citados por Juárez-López y Sala-Berga, 2011) radica en que ésta es más cuantitativa que cualitativa y consideran, de hecho, que el recuerdo de niños de 3 años, por ejemplo, es bastante exacto, sin embargo menos minucioso que el de los niños de 8 años. En este sentido, Echeburúa y Guerricaechevarría (2000) mencionan que de igual forma que en los adultos, el recuerdo de los niños disminuye en precisión a medida que transcurre el tiempo, por lo que el niño recuerda menos información, pero no por ello menos precisa, especialmente si ha transcurrido corto tiempo entre el acontecimiento y la narración de su recuerdo.

Ante sucesos o situaciones vividas y su posterior remembranza existe la posibilidad de que los recuerdos sean reales y exista exactitud en las características que hacen parte de ese recuerdo, pero cuando al momento de hacer remembranza de situaciones vividas o simuladas que difieren parcial o totalmente de la realidad experimentada se presentan las denominas Falsas Memorias (FM). Según Mojardín-Heráldez (2008), las FM se presentan como pequeñas desviaciones de forma, lo que conlleva al cambio de las características de un evento experimentado, como sería el caso de afirmar que un delincuente al momento de cometer un delito llevaba una prenda que 
en la realidad no utilizaba; y en otros eventos se pueden presentar verdaderas modificaciones de los hechos vividos como sería el caso de denunciar un delito que no tuvo ocurrencia.

En igual sentido, otros autores consideran que las FM son reportes memorísticos que difieren parcial o totalmente de los eventos experimentados (Miramontes, Stein y Mojardín, 2010) o como recordar hechos que no han ocurrido o recordarlos de forma diferente a como sucedieron (Payne et al., 1996, Roediger y MacDermott, 1996, citados por García-Bajos y Migueles, 1998). Para Ibabe (2008) la FM no es cualquier error de memoria, se refiere a los casos en que una persona cree recordar un hecho que no ocurrió realmente o nombra un objeto inexistente.

En tanto para autores como Reed y Ellis (2007), las FM son distorsiones de la memoria, puesto que las personas recuerdan cosas de manera muy distinta a cómo sucedieron en realidad $\mathrm{y}$, en otras, se recuerdan algunas que nunca ocurrieron. Las FM se pueden presentar por una información relacionada, por ejemplo, una mujer ve a una amiga en el cine por unos momentos y, entre otras cosas, la mujer está pensando en su novio, más tarde ella recordará que vio a su novio en el cine, cuando en realidad él nunca estuvo allí.

En 2007, Reed y Ellis consideraron que la información relacionada es usada en experimentos como listas de palabras asociadas a un solo artículo básico. Por ejemplo una lista comprende las palabras alfiler, coser, hilo, ropa, inyección, suero y paja, y todas tiene que ver con aguja. Se presenta a los participantes una lista así, de 12 a 25 palabras, sin que este en la lista la palabra aguja, sin embargo cuando se les requiere a los participantes que recuerden las palabras escuchadas, la probabilidad de recordar en falso el artículo básico es tan alta como la de que recuerden correctamente los artículos que si escucharon. 
La explicación entregada por estos autores, de la causa por la cual la información se recuerda en falso es que en el trascurso de la comprensión del material presentado, llega a la mente la información relacionada, por lo tanto ésta se infiere y, en tal sentido, dicha información relacionada está presente durante la vivencia original. No obstante, no forma parte de la vivencia que se solicita en la prueba de memoria y la recopilación que se presentó en un recuerdo falso.

Las implicaciones de las FM en el ámbito legal deben tener una alta consideración, puesto que el tomar la decisión de culpabilidad o inocencia de un procesado dependerá de si el testimonio entregado por la victima, victimario y/o testigos se considera ajustado a los hechos reales o no.

En este aspecto Dalla-Barba (2005) indica que en los Estados Unidos hay 75.000 juicios penales por año que se deciden de acuerdo con la declaración de testigos oculares. Un estudio reciente determinó que 36 de 40 casos juzgados con base en los testimonios de sujetos que presenciaron un hecho resultaron en sentencias inadecuadas. Las evidencias de ADN establecieron la inocencia de personas encarceladas injustamente debido a testimonios no certeros. Este porcentaje de error, que asciende al 90\%, genera la necesidad de una concientización inmediata. Es imperante comprender qué implican los falsos recuerdos en función de relativizar sus efectos.

\section{Clasificación de las falsas memorias.}

Las FM se clasifican en dos, memorias implantadas y memorias espontáneas, la diferencia entre ellas se establece por los recursos que les da origen. La primera de ellas, memorias implantadas son reportes memorísticos creados por la influencia de información externa, por ejemplo un comentario equívoco de un tercero. Las memorias espontáneas son reportes 
memorísticos alterados por aspectos internos, propios del funcionamiento de la memoria, un ejemplo sería la inferencia (Mojardín-Heráldez, 2007).

En la clasificación de las FM (espontáneas e implantadas) de acuerdo con PinchanskiFachler, Víquez-Hidalgo y Zeledón-Grande (2004) y Mojardín-Heráldez (2007), los falsos recuerdos implantados resultan de la exposición de una persona a información engañosa e incorporación de la misma a su repertorio de conocimiento. Su fuente de origen es un tercer recurso de información (por ejemplo un comentario de una persona sobre un evento particular o una pregunta sugerente de parte del ministerio público).

En tanto, la implantación de recuerdos falsos obedece tanto a mecanismos cognitivos como a mecanismos socioculturales. Los recuerdos falsos espontáneos resultan de mecanismos internos de distorsión de memoria. Su fuente de origen puede ser cualquier mecanismo memorístico de la elaboración de la información. La invitación del abogado o el ministerio público para que el testigo haga el esfuerzo de reportar con claridad los hechos puede ser el detonador para la creación de falsos recuerdos espontáneos (Pinchanski-Fachler, Víquez-Hidalgo y Zeledón-Grande, 2004, Mojardín-Heráldez, 2007).

Estos dos tipos de FM son de suma preocupación para la psicología y para el ámbito judicial, puesto que devela la facilidad con que las personas pueden tener influencia de terceros para alterar la estructura y contenidos de los recuerdos y con ello los comportamientos. Los efectos de los dos tipos de FM son contraproducentes y ejemplos de cómo han influido de forma negativa en la vida de múltiples personas acusadas falsamente (Ceci y Bruck, 1995, citado por Mojardín-Heráldez, 2007).

En diferentes casos reportados por Loftus (1997), en los que varias mujeres que asistieron a psicoterapia por diversos motivos, terminaron creyendo que los recuerdos reprimidos que sus 
psicoterapeutas les ayudaron a recordar, como el haber sido abusadas por múltiples personas, haber participado en ritos satánicos, entre otras cosas, son claros ejemplos de la implantación (sugestión) de FM.

En cuanto al origen de las FM, Davies y Loftus (2006, citados por Manzanero, 2008), indican que existen tres tipos de FM: a) memorias selectivas o falsos selectivos en la información, b) memorias falsas sobre hechos que los sujetos no han vivido realmente, c) distorsiones o alteraciones de la memoria de hechos vividos por los sujetos. Asimismo, estos autores indican que, las posibles fuentes generadoras de estas FM son los procesos inferenciales y esquemáticos, así como las fuentes de información sesgadas.

En investigaciones como las de Christianson y Hübinette (1993, y de Yuille y Cutshall, 1986, citados por García-Bajos y Migueles, 1999) en las que se evalúo la memoria y las FM, comparando sujetos que hayan vivido situaciones en las que la emoción haya estado implícita versus sujetos con los que se trabajo en situaciones neutras o de laboratorio, se encontró que, los primeros, presentan mayores recuerdos detallados y precisos del suceso, son menos propensos o susceptibles a preguntas engañosas y presentan, en el tiempo, un mantenimiento claro de la información. De igual forma, estos estudios encontraron que los errores estaban más limitados a los detalles y aspectos específicos relacionados con la descripción de personas.

En tanto, Kassin, Ellsworth y Smith (1989, Clifford y Hollin, 1981 y Loftus y Burns, 1982, citados por García-Bajos y Migueles, 1999), consideraron que el estrés motivado por los sucesos emocionales empeora la memoria, en concordancia con trabajos de laboratorio que comparan situaciones emocionales y neutras simulando los sucesos mediante diapositivas o películas.

\section{Implantación de falsas memorias.}


En lo relacionado con la información sugerida para que se presenten FM, Manzanero (2001) indica que si luego de ocurrido un suceso se le proporciona a quien lo observó una información segada, ésta puede incorporarse a su memoria original. En el mismo sentido, manifiesta que uno de los momentos más delicados en los que puede modificarse la memoria, en el caso de testigos, por información sugerida es cuando se toma la declaración, para lo cual, y con el objeto de obtener mayor cantidad de información posible, normalmente se recurre a la formulación de preguntas que proporcionen más información que un relato libre de los sucedido. Como contrapartida, por el uso de esas preguntas sugestivas los declarantes al contestarlas cometen inexactitudes: errores de comisión (Loftus, 1975, citada por Manzanero, 2001).

En la implantación de FM, una de las preguntas más importantes es ¿y cómo se forman o se implantan las FM?, teniendo en cuenta el estudio de Kassin y Kiechelun (1996, citado por Loftus, 1997), en el cual estudiaron las reacciones de individuos acusados falsamente de haber estropeado un ordenador al pulsar una tecla equivocada. Los participantes inocentes negaron de entrada los cargos, pero cuando un cómplice afirmó que ella les había visto ejecutando la acción, varios participantes cambiaron la confesión, internalizaron la culpabilidad por haberlo hecho y ofrecieron detalles fabulados consistentes con tal creencia. Estos hallazgos muestran que la acusación de evidencia falsa puede inducir a la gente a aceptar culpabilidad por un delito que no cometieron e incluso a desarrollar memorias para soportar sus sentimientos de culpa.

De acuerdo con Loftus (1997) la creación de una FM es más probable cuando están presentes los siguientes factores externos, bien sea en una situación experimental, en un contexto terapéutico o durante las actividades cotidianas; a) se dan exigencias sociales para que los individuos recuerden algún hecho; b) la construcción de la memoria mediante la imaginación de 
acontecimientos puede ser animada explícitamente cuando la gente tiene recuerdos dudosos; y c) los sujetos pueden ser animados a no juzgar si sus construcciones son reales o no.

Por su parte Manzanero (2001), considera que la sugerencia o insinuación de información falsa deteriora el recuerdo que los sujetos tienen sobre el suceso, sin que afecte en conjunto la descripción. Igualmente, una vez proporcionada información falsa a la persona la declaración disminuye en la cantidad de información exacta, con un aumento de distorsiones y falsa alarmas incluso de información ajena a los detalles falsos sugeridos.

De acuerdo con Pinchanski-Fachler, Víquez-Hidalgo y Zeledón-Grande (2004), en el área judicial, y con la pretensión del registro de la información más nutrida y más clara, los policías, los abogados y los ministerios públicos desarrollan entrevistas a través de las cuales pueden, involuntariamente, provocar el reporte de falsos testimonios. Algunas veces, el tipo de preguntas que se plantea a la víctima y testigos son sugerentes o preguntas que demandan la elaboración sobre la experiencia vivida y el espacio en que se formulan éstas son espacios de mucha carga emocional.

Brainerd y Reyna (1995, citado por Pinchanski-Fachler, Víquez-Hidalgo y Zeledón-Grande, 2004) proponen que los mecanismos de conformación de los falsos recuerdos no son diferentes a los mecanismos que conforman los recuerdos verdaderos. El origen de ambos depende del tipo de información que se memoriza (de sentido común o información más complicada), como se memoriza (vía oral, táctil, auditiva, visual o en forma combinada de algunas de ellas), cuando se evalúa la memoria (inmediatamente o tiempo después de sucedido el hecho) y el procedimiento que se sigue para ello (vía reconocimiento o recuerdo libre).

Según estos autores, la implantación de FM se da con mayor facilidad cuando los interrogatorios se ejecutan considerable tiempo después de pasado el delito y las preguntas que 
se formulan a los testigos sugieren respuestas. Las preguntas sugerentes son aquellas en cuya formulación se provee información que el testigo y/o la víctima no han reportado.

La implantación de FM es posible tanto en niños como en adultos. Sobre las diferencias de edad y la posibilidad de implantar FM no hay una posición definitiva. Algunos estudios han logrado demostrar que los niños son más fáciles de engañar y de ser persuadidos para reportar información sugerida (Ceci y Bruck, 1993, citado por Pinchanski-Fachler, Víquez-Hidalgo y Zeledón-Grande, 2004). Otros estudios demuestran que dependiendo de la información que hay que reportar y el mecanismo memorístico que permitirá la recuperación de esa información, los adultos pueden ser más susceptibles a la implantación de FM, además, los adultos pueden ser más susceptibles a la implantación de FM, dependiendo de las circunstancias que se provea esa información, la familiaridad de las personas con el delito y la congruencia de la información proveída con el significado global de éste, se podría decir que hay ligeros aumentos en la probabilidad de implantación de recuerdos con el aumento de la edad.

En cuanto a las formas de implantar las FM en un testigo o víctima que está dando un testimonio son las entrevistas sugestivas. En una revisión sistemática realizada por HoffmeisterTorres (2003), encontró que las entrevistas repetidas pueden contaminar la memoria de los niños, sin embargo los estudios muestran una mejoría en la recolección de datos cuando las entrevistas no son sugestivas, en tanto, las entrevistas sugestivas múltiples pueden llevar a distorsiones importantes y falsas memorias. Estas falsas memoria pueden desaparecer con el tiempo, pero si ya han quedado documentadas en un reporte profesional y legal, es muy difícil o imposible evitar sus consecuencias.

De acuerdo con Pinchanski-Fachler, Víquez-Hidalgo y Zeledón-Grande (2004), algunas veces en el ámbito legal, el tipo de preguntas que se plantea a la víctima y testigos en una 
entrevista son sugerentes o preguntas que demandan la elaboración sobre la experiencia vivida y el espacio en que se formulan éstas son espacios de mucha carga emocional. Estos autores recalcan que según las investigaciones, la implantación de recuerdos falsos se da con mayor facilidad cuando los interrogatorios se ejecutan mucho tiempo después de pasado el delito y las preguntas que se formulan a los testigos sugieren respuestas. Las preguntas sugerentes son aquellas en cuya formulación se provee información que el testigo y/o la víctima no han reportado.

Por su parte, Bruck y Ceci (1999, citados por Juárez-López y Sala-Berga, 2011), consideran que en las entrevistas, algunas expresiones de apoyo por parte del entrevistador pueden llegar a ser sugestivas, suponiendo un riesgo para la fiabilidad de la declaración del entrevistado (por ejemplo, "te preguntaré por una cosa muy importante", "no tienes que tener miedo de explicarlo", "te sentirás mejor cuando lo expliques"). Este ambiente puede propiciar que la persona aporte información falsa si se le pregunta de forma capciosa por un acontecimiento que pasó hace algún tiempo.

Con respecto a los niños y la implantación de FM en entrevistas o interrogatorios, de acuerdo con Juárez-López y Sala-Berga, (2011), una entrevista se hace en su mayoría a través de preguntas. Si el entrevistador no ha sido reflexivo con la tipología de las preguntas y con la forma en que se formulan al niño, muy probablemente provocará que la dirección y la sugestión sesgada sean las que dicten el camino del relato de los presuntos hechos. La actitud del entrevistador en la entrevista, sus creencias y la atmósfera que cree también pueden influir o sugestionar el testimonio del niño.

En los niños de preescolar las FM pueden ser implantas de acuerdo a los postulados de Pole y Linday, (1995, citados por Cantón y Cortes, 2008), quienes llevaron a cabo una investigación 
en la que niños de preescolar jugaban durante dieciséis minutos en el laboratorio con "Mr. Ciencia", cuatro meses después enviaron a los padres un libro de historietas especialmente diseñado para cada niño, en el que se describía su visita al laboratorio. Estas historietas describían dos experimentos observados por el niño, pero también otros dos que no habían visto, y las historietas terminaban con una explicación totalmente inventada de cómo se había despedido Mr. Ciencia del niño al final del experimento, ("Mr. Ciencia le limpió a ... las manos y la cara con una toallita de papel. Se le acercó a la boca de... y sabía realmente mal”) y los padres leyeron tres veces las historietas a sus hijos.

Al momento de realizarse las entrevistas, más de la mitad de los niños contestaron a las preguntas de forma equivocada, además, sus respuestas iban adornadas con sucesos que no habían sido parte de la experiencia. A medida que se fueron repitiendo las entrevistas, las respuestas inexactas fueron aumentando. Ante un suceso inventado por los investigadores, aproximadamente el $71 \%$ de los niños indicaron que la experiencia había sido real e insistían en sus afirmaciones a pesar de que se les había advertido de que algunas de las cosas que se les había leído no había ocurrido y de que se les había entrenado para que contestaran con un no cuando les preguntaran por sucesos que no habían ocurrido.

En dos estudios realizados por Goodman y Reed (1986) y Goodman et al (2006), al hacer preguntas abiertas y sugestivas, hallaron que los menores entre los tres y cuatro años eran más sugestionables que los de cinco a seis años, señalando que ambos grupos se acercan al 100\% de precisión cuando responden a preguntas cerradas y concisas como por ejemplo ¿esa persona te besó?", "¿esa persona te pegó?".

En otro estudio, Bruck, Ceci, Francoeur y Barr (1995, citados por Juárez-López y SalaBerga, 2011), trabajaron con niños de 5 años que visitaron al pediatra para que les hiciera un 
reconocimiento físico, les diera una vacuna oral y les pusiera una inyección. Inmediatamente, un ayudante les leía un cuento y les daba un regalo. Después de un año, algunos de los niños fueron entrevistados en tres ocasiones en las cuales se les transmitía información falsa (el pediatra les había leído una historia y les había hecho un regalo, mientras que el ayudante era el que les había dado la vacuna y puesto la inyección). A la cuarta entrevista, los niños que no habían recibido información falsa, hicieron un relato exacto sobre las acciones del pediatra y del ayudante, mientras que los que recibieron información falsa cometieron más errores, incorporaron sugerencias capciosas e incluyeron actividades del ayudante que no se les había sugerido.

Los estudios de Brainerd y Mojardín (1998), realizados con niños y adultos indicaron que una vez reportados los recuerdos falsos y los verdaderos sobre un evento, éstos se consolidan y tienden a repetirse en ocasiones posteriores. Lo más preocupante de esto para la procuración de justicia, es que según los resultados de esos estudios los falsos recuerdos son más resistentes al olvido que los recuerdos verdaderos. Resultados similares fueron reportados por Brainerd, Reyna y Brandse (1995, McDermott, 1996, Brainerd y Poole, 1997 y Mojardín, 1998, citado por Morjadín-Heráldez, 1999).

Los estudios realizados por Hernández y Roebers (2007), tenían por objetivo replicar una serie de estudios realizados en Alemania que indicaban, por una parte, la existencia de un efecto positivo del uso de incentivos en la regulación estratégica de los testimonios emitidos por niños de 6, 7 y 8 años, en respuesta a diferentes tipos de preguntas (contestables e incontestables, formuladas de forma abierta y engañosa), cuando se les permitía contestar "no lo sé". Por otra parte, los estudios indicaron de igual forma que los efectos de esta incentivación (monedas de cartón canjeables por juguetes) eran debidos principalmente a la concurrencia simultánea del incentivo más el feedback, y no sólo al efecto independiente del feedback o del incentivo. 
Los resultados de los estudios de Hernández y Roebers (2007), mostraron resultados consistentes con las investigaciones previas (relativos a las diferencias asociadas a la edad, y la regulación estratégica de las preguntas contestables e incontestables engañosas), pero también, una serie de resultados inconsistentes (la ausencia de efectos reguladores en el caso de las preguntas contestables e incontestables abiertas, y la naturaleza específica de la regulación estratégica en las preguntas contestables engañosas). En síntesis, se podría decir que mientras en estudios previos, los efectos de las manipulaciones experimentales afectaron positivamente la regulación estratégica en todos los tipos de preguntas formuladas, en el presente estudio dicho efecto sólo ha tenido lugar en el caso de las preguntas engañosas (contestables e incontestables). Los participantes del estudio replicador, parecen haber procesado de una manera distinta las preguntas abiertas y las engañosas.

Por su parte Rodriguez, Serrano, Mayorga-Tobar y Palacios Pinzón, (2006), indican que existe incidencia de la variable de sugestionabilidad sobre el testimonio infantil, alterando la información original que debería ser reportada, debido a la presencia de un señuelo en las preguntas lo que lleva al menor a distorsionar sus respuestas.

De acuerdo con Yuille, Hunter, Joffe y Zaparniuk (1993, citados por Morjadín-Heráldez, 1999) en estudios en los que sometieron a prueba la entrevista cognitiva comparándola con los procedimientos normales de interrogatorio (en los que también se evitaron las preguntas sugerentes), sus resultados demostraron una tendencia mayor de los participantes a reportar información falsa cuando fueron sometidos al interrogatorio común, que cuando fueron sometidos a la entrevista cognitiva. La entrevista cognitiva produjo reportes memorísticos mucho más precisos, que los que produjo la entrevista común. Según Ceci y Bruck (1995) la solidez de los resultados que emanan de la aplicación de la entrevista cognitiva ha dado confianza a los 
abogados para luchar por que su aplicación sea oficializada en numerosos estados de los Estados Unidos y algunos países de Europa.

Día a día los procedimientos para la valoración de la credibilidad de testimonios son cada vez más importantes, con la necesidad de procurar procesos judiciales adecuados y enmarcados en la ley, sin permitir que los testimonios falsos tengan cabida al momento de determinar la culpabilidad o no de una persona que está siendo juzgada. Sin embargo, la realidad de las investigaciones y de los juicios penales ha llegado a indicar que se deben desarrollar técnicas más eficientes. Por ejemplo Strömwall, Bengtsson, Leander (2004, citados por Manzanero, 2009), encontraron, en un estudio realizado con niños entre los 10-13 años, que el Análisis de Contenido Basado en Criterios (CBCA) solo permitió clasificar un 54\% de los relatos, por lo que su capacidad para discriminar no resultó significativa. De los 43 relatos reales solo 19 (44\%) fueron correctamente evaluados, mientras el de los 44 imaginados fueron correctamente identificados $28(64 \%)$. 


\section{Objetivos}

\section{Objetivo general}

Comparar si existen diferencias en los recuerdos de una actividad presentada a niños y niñas

de 3 a 5 años de edad, a partir de una entrevista con preguntas sugestivas y de una entrevista con preguntas no sugestivas.

\section{Objetivos específicos}

1. Medir los tipos de recuerdos que se generen en cada uno de los participantes.

2. Medir en los grupos de estudio los recuerdos generados a través de la entrevista con preguntas sugestivas y entrevista con preguntas no sugestivas.

3. Establecer la presencia de implantación de falsas memorias de los hechos vividos. 


\section{Variables}

Las variables tenidas en cuenta en el presente estudio fueron falsas memorias y tipo de entrevista (entrevista con preguntas sugestivas y entrevista con preguntas no sugestivas). A continuación se conceptualiza y operacionaliza cada una de ellas:

Variable dependiente

\section{Las Falsas Memorias}

Para este estudio se entiende por falsas memorias, de acuerdo con Payne et al., (1996, Roediger y MacDermott, 1996, citados por Gracia-Bajos y Migueles, 1997), el recordar hechos que no han ocurrido o recordarlos de forma diferente a como sucedieron.

Las falsas memorias serán medidas por el número de falsos recuerdos que los participantes presenten en las entrevistas aplicadas.

Variables independientes: Tipo de entrevista.

\section{Entrevista sugestiva}

En esta investigación se entiende por entrevista con preguntas sugestivas, aquella entrevista que utiliza preguntas que sesgan u orientan el recuerdo del entrevistado.

\section{Entrevista con preguntas no sugestivas}

La entrevista con preguntas no sugestiva, es aquella entrevista que utiliza preguntas objetivas que no sesgan u orienten las respuestas de quien está siendo entrevistado. 


\section{Hipótesis}

Para la presente investigación cuantitativa con un diseño cuasi experimental, se plantean las siguientes hipótesis de trabajo e hipótesis nulas.

Existen diferencias en los recuerdos de niños y niñas de 3 a 3, 11 años de edad, que han sido expuestos a una actividad lúdica, a partir del tipo de entrevista.

Hi: $\bar{X}$ Es $\neq \bar{X} \mathrm{E} \sim \mathrm{s}$

No existen diferencias en los recuerdos de niños y niñas de 3 a 3, 11 años de edad, que han sido expuestos a una actividad lúdica, a partir del tipo de entrevista.

Ho: $\bar{X}$ Es $=\bar{X} \mathrm{E} \sim \mathrm{S}$

Existen diferencias en los recuerdos de niños y niñas de 4 a 4,11 años de edad, que han sido expuestos a una actividad lúdica, a partir del tipo de entrevista.

Hi: $\bar{X}$ Es $\neq \bar{X}$ E s

No existen diferencias en los recuerdos de niños y niñas de 4 a 4,11 años de edad, que han sido expuestos a una actividad lúdica, a partir del tipo de entrevista.

Ho: $\bar{X}$ Es $=\bar{X} \mathrm{E} \sim \mathrm{s}$

Existen diferencias en los recuerdos de niños y niñas de 5 a 5,11 años de edad, que han sido expuestos a una actividad lúdica, a partir del tipo de entrevista.

Hi: $\bar{X}$ Es $\neq \bar{X}$ E s

No existen diferencias en los recuerdos de niños y niñas de 5 a 5,11 años de edad, que han sido expuestos a una actividad lúdica, a partir del tipo de entrevista.

Ho: $\bar{X} \mathrm{Es}=\bar{X} \mathrm{E} \sim \mathrm{s}$

Existen diferencias en los recuerdos de los niños y niñas del grupo A (3 a 3,11 años de edad), que han sido expuestos a una actividad lúdica, a partir del tipo de entrevista, con los niños 
y niñas del grupo B (4 a 4,11 años de edad), que han sido expuestos a una actividad lúdica, a partir del tipo de entrevista.

Hi: $\bar{X}_{\text {A Es }} \neq \bar{X}_{\mathrm{BE} \sim \mathrm{s}}$

No existen diferencias en los recuerdos de niños y niñas del grupo A (3 a 3,11 años de edad), que han sido expuestos a una actividad lúdica, a partir del tipo de entrevista, con los niños y niñas del grupo B (4 a 4,11 años de edad), que han sido expuestos a una actividad lúdica, a partir del tipo de entrevista.

Ho: $\bar{X}_{\mathrm{A}} \mathrm{Es}=\bar{X}_{\mathrm{BE} \sim \mathrm{s}}$

Existen diferencias en los recuerdos de niños y niñas del grupo A (3 a 3,11 años de edad), que han sido expuestos a una actividad lúdica, a partir del tipo de entrevista con los niños y niñas del grupo C (5 a 5,11 años de edad), que han sido expuestos a una actividad lúdica, a partir del tipo de entrevista.

\section{Hi: $\bar{X}_{\text {A Es }} \neq \bar{X}_{\mathrm{CE} \sim \mathrm{s}}$}

No existen diferencias en los recuerdos de niños y niñas del grupo A de niños y niñas 3 a 3,11 años de edad, que han sido expuestos a una actividad lúdica, a partir del tipo de entrevista, con los niños y niñas del grupo C (5 a 5,11 años de edad), que han sido expuestos a una actividad lúdica, a partir del tipo de entrevista.

$\mathrm{Hi}: \bar{X}_{\mathrm{A}} \mathrm{Es}=\bar{X}_{\mathrm{CE} \sim \mathrm{s}}$

Existen diferencias en los recuerdos de niños y niñas del grupo de B (4 a 4,11 años de edad), que han sido expuestos a una actividad lúdica, a partir del tipo de entrevista con los niños y niñas del grupo C (5 a 5,11 años de edad), que han sido expuestos a una actividad lúdica, a partir del tipo de entrevista.

$\mathrm{Hi}: \bar{X}_{\mathrm{B}} \mathrm{Es} \neq \bar{X}_{\mathrm{CE} \sim \mathrm{s}}$ 
No existen diferencias en los recuerdos de niños y niñas del grupo B (4 a 4,11años de edad), que han sido expuestos a una actividad lúdica, a partir del tipo de entrevista, con los niños y niñas del grupo C (5 a 5,11 años de edad), que han sido expuestos a una actividad lúdica, a partir del tipo de entrevista.

Ho: $\bar{X}_{\text {B }}$ Es $=\bar{X}_{\mathrm{CE} \sim \mathrm{s}}$ 


\section{Método}

\section{Tipo de investigación y diseño}

Es una investigación cuantitativa, con un diseño cuasi experimental, que consiste en utilizar seis grupos divididos en tres rangos de edad, cada rango tiene un grupo experimental y un grupo de comparación, sin asignación al azar ni emparejamiento, (Hernández, Fernández y Baptista, 2010). Para determinar si el tratamiento es efectivo, se comparan las tasas de la conducta blanco en los grupos experimental y de comparación (Kazdin, 1996).

En la presente investigación, se trabajará con tres grupos distinguidos con las letras A, B y $\mathrm{C}$, cada uno de los cuales tendrán un grupo experimental $\left(\mathrm{G}_{1}\right)$ y un grupo de comparación $\left(\mathrm{G}_{2}\right)$, como se ilustra en la Tabla 1.

\section{Tabla 1.}

Diseño de los grupos experimentales y de comparación con postest.

\begin{tabular}{|c|c|c|}
\hline Grupo A & Grupo B & Grupo C \\
\hline $\mathrm{G}_{1} \times \mathrm{O}$ & $\begin{array}{l}\mathrm{G}_{1} \mathrm{X} \\
\mathrm{O}\end{array}$ & $\mathrm{G}_{1} \times \mathrm{O}$ \\
\hline $\mathrm{G}_{2}-\mathrm{O}$ & $\begin{array}{l}\mathrm{G}_{2}- \\
\mathrm{O}\end{array}$ & $\mathrm{G}_{2}-\mathrm{O}$ \\
\hline
\end{tabular}

\section{Participantes}

El estudio contó con la participación de 36 niños y niñas entre los tres y cinco años de edad, que hacían parte del alumnado de un jardín infantil privado de localidad de Teusaquillo (Bogotá).

Para la participación de los niños y niñas se realizó una reunión con los tutores de los niños y niñas, en la cual se entrego la información con respecto al estudio y se solicito, a aquellos padres que permitieran participar a sus hijos o representados, que firmara un consentimiento 
informado, elaborado de acuerdo a las normas éticas para la investigación con humanos de la American Psychological Association (2002), (Ver apendice A).

La conformación de los grupos experimentales y de comparación se realizó de acuerdo a como se muestra en la Tabla 2.

Tabla 2.

Conformación grupos experimentales y de comparación.

\begin{tabular}{ccc}
\hline $\begin{array}{c}\text { Grupos de } \\
\text { Edades }\end{array}$ & Entrevista A & Entrevista B \\
\hline 3,0 a 3,11 años & 6 niños & 6 niños \\
\hline 4,0 a 4,11 años & 6 niños & 6 niños \\
\hline 5,0 a 5,11 años & 6 niños & 6 niños \\
\hline
\end{tabular}

Para la conformación de los grupos experimentales y de comparación, se asignaron los niños y niñas de forma aleatoria a cada uno de ellos. Para la asignación de los participantes a cada grupo, se utilizó una lista y se hizo la escogencia al azar, teniendo en cuenta que el número de niños y niñas asignado a cada uno de los grupos fuera el mismo.

Como se mencionó anteriormente, el estudio contó con la participación total de 36 niños y niñas, y sus características socio-demográficas se describen en la Tabla 3. Con respecto al número de participantes por sexo, se tiene que el $47.7 \%$ de los participantes fueron niñas. En cuando al nivel socioeconómico, el mayor porcentaje de los participantes estuvo ubicado en el estrato $3(58.3 \%)$ mientras que el menor porcentaje se ubico en el estrato dos (2.7\%). Para el nivel educativo de los participantes, el $80.5 \%$ se encontraban cursando pre-jardín y kínder. 
Tabla 3

Número de participantes por sexo, nivel socioeconómico y nivel educativo

\begin{tabular}{ccc}
\hline Característica & Categoría & N \\
\hline \multirow{2}{*}{ Sexo } & Femenino & 17 \\
& Masculino & 19 \\
\hline \multirow{3}{*}{ Nivel Socioeconómico } & Estrato 2 & 1 \\
& Estrado 3 & 21 \\
& Estrato 4 & 14 \\
\hline \multirow{2}{*}{ Nivel Educativo } & Párvulos & 7 \\
& Pre-jardín & 12 \\
& Kínder & 17 \\
\hline
\end{tabular}

\section{Instrumentos}

Los instrumentos utilizados para esta investigación fueron dos tipos de entrevistas, una que contenía preguntas sugestivas (Ver Apéndice B) y otra de preguntas no sugestivas (Ver Apéndice C).

Las dos entrevistas fueron diseñadas por los autores de la investigación y posteriormente fue sometida a una validación de contenido por jueces expertos. Cada uno de los instrumentos viene acompañado de un protocolo de aplicación, en el cuál se podrá evidenciar los pasos que se deben seguir para su aplicación

\section{Procedimiento}

El desarrollo de la investigación se realizó en ocho pasos, descritos a continuación:

El primer paso consistió en establecer los elementos o aspectos básicos que dan estructura y direccionamiento a una investigación, se planteó el problema o tema a investigar, los objetivos, variables, hipótesis, tipo de investigación y diseño, se estableció la población y se realizó la revisión de literatura, con la cual se extrajo los aportes más significativos que le entregó un sustento tanto teórico, empírico y metodológico a la investigación. 
En el segundo paso, se estableció contacto con una institución educativa de la ciudad de Bogotá, que aceptó participar en la investigación. Para contextualizar a las directivas del colegio de la actividad que se iba a realizar, se cito a una reunión, posterior a su aceptación y de entregar los permisos correspondientes, se contactó a los padres o tutores de los estudiantes y se les dio a conocer el objetivo de la investigación, detallando cómo su hijo participaría en ella y las normas éticas que aplicarían en el desarrollo de ésta. Al finalizar la reunión se solicitó, a aquellos padres que permitieron a sus hijos participar, firmar el consentimiento informado.

Posteriormente (paso tres) se elaboro el libreto y montaje de la obra de títeres "la vaquita desobediente", que se presentó a los participantes de la investigación. Con base en la obra se diseñaron dos entrevistas, con preguntas sugestivas y no sugestivas respectivamente, los cuáles ayudaron o permitieron recoger la información necesaria que ayudó a dar respuesta a la pregunta de investigación, así como también aceptar o rechazar las hipótesis nulas. Para la validación de contenido de los instrumentos, se recurrió a cinco jueces expertos.

Como paso cuatro se realizó una prueba de pilotaje que sirvió de base para mitigar errores en la presentación de la obra de títeres y en la aplicación de las entrevistas A y B a los participantes de la investigación.

En el paso quinto se coordinó con las directivas del jardín, las fechas en las cuáles se llevaría a cabo la actividad. Posteriormente se reunió a los niños y niñas y se les presentó la obra de títeres. Al día siguiente, después de la actividad, se llevó a cabo las rondas de entrevistas (paso seis), para conformar los grupos, se aplicó la división establecida en la Tabla 2, en el apartado de participantes.

Seguido, en el paso siete, se codificó la información de las entrevistas y se creó una base de datos que permitió realizar el análisis de los mismos, tanto de las variables socio-demográficas 
como de los ítems de las entrevistas. Para finalizar, en el paso ocho, se realizó el análisis de los resultados encontrados, haciendo la comparación entre los grupos y subgrupos, y se hizo la contrastación de los resultados a la luz de la teoría, los aspectos metodológicos, las hipótesis y la pregunta de investigación (discusión).

\section{Análisis de datos}

Los resultados de las entrevistas fueron analizadas estadísticamente mediante la prueba paramétrica Anova de dos factores por medio del programa estadístico SPSS. Esta prueba se utiliza con datos separados en categorías formadas de acuerdo a dos factores.

\section{Aspectos éticos}

El estudio se basó en los postulados para la investigación con humanos de la Asociación Americana de Psicología descritos por Sales y Folkman (2003). La investigación se llevó a cabo con respeto y consideración de la dignidad y bienestar de los participantes y con el conocimiento de las regulaciones gubernamentales y la ética profesional con respecto a la estudio de la conducta con participantes humanos.

Se estableció un acuerdo claro y justo con los tutores de los participantes, antes de su participación, que aclara las obligaciones y responsabilidades de cada uno. El investigador tiene la obligación de honrar todas las promesas y compromisos incluidos en ese acuerdo. Los investigadores informaron a los tutores de los participantes de todos los aspectos de la investigación que pudiesen influir en la voluntad de participar.

Se protegió al participante de cualquier malestar físico y/o mental, daño y/o peligro que puedan derivarse de los procedimientos de la investigación. Si existen tales riesgos, el investigador informa a los participantes de ese hecho. El participante debe ser informado que 
después de terminar la investigación, durante un plazo razonable, debe contactarse con los investigadores por si presenta estrés, daño potencial, y/o preguntas o dudas.

Una vez recogidos los datos, se proporcionó a los tutores de los participantes información sobre la naturaleza del estudio y los intentos de eliminar cualquier malentendido que pueda haber surgido. Cuando los valores científicos o humanos justifican retrasar o negar esta información, el investigador incurre en una responsabilidad especial para supervisar la investigación y para asegurar que no hay consecuencias perjudiciales para el participante.

La información obtenida acerca de un participante durante el curso de la investigación es confidencial a menos que se acuerde lo contrario con antelación. Cuando existe la posibilidad de que otros puedan tener acceso a esa información, esta posibilidad, junto con los planes para la protección de la confidencialidad, se explica a los tutores de los participantes como parte del procedimiento para la obtención del consentimiento informado. En la presente investigación la información tendrá libre acceso para las personas implicadas, tutores de los estudiantes, asesor y profesionales de la institución académica de la cual se obtuvo la muestra.

Se mantiene la identidad anónima de cada uno de los participantes y de la institución de la que fue extraída la muestra, solo se evidencia en la base de datos la información sociodemográfica y ésta es conocida únicamente por las personas involucradas directamente con la investigación (estudiantes y asesora). 


\section{Resultados}

El presente análisis de datos incluye cuatro partes, la primera es un análisis de los resultados obtenidos por parte de la validación de jueces expertos, para éste propósito se utilizó el coeficiente Alfa de Cronbach y se tuvieron en cuenta tres dimensiones: pertinencia, coherencia y claridad.

La segunda parte es un análisis comparativo de los grupos (inter e intra grupos) establecidos en el diseño de investigación, con el cual se buscó establecer diferencias en cuanto a sí se logró o no la sugestión de los recuerdos de los participantes del grupo experimental.

La tercera parte, es un análisis descriptivo de la pregunta número 10, que tuvo por objetivo permitir una narración abierta de lo que el niño o niña recordó de la obra de títeres, esta pregunta se hizo tanto en la entrevista con preguntas sugestivas y como en la entrevista con preguntas no sugestivas.

Finalmente, la cuarta parte, es un análisis descriptivo de las observaciones conductuales que se registraron al momento de realizar las entrevistas.

Los resultados de la comparación de medias de muestras independientes se realizaron mediante la prueba paramétrica Anova de dos factores por medio del programa estadístico SPSS.

Esta prueba se utiliza con datos separados en categorías formadas de acuerdo a dos factores; se considerara un valor de significación de $p<0.05$.

\section{Validación por jueces expertos}

Para la entrevista no sugestiva (A) en las dimensiones coherencia, pertinencia y claridad, en la tabla 4 se puede observar que la confiabilidad es significativamente alta, lo que indica que los 10 ítems de los que se compone el instrumento son coherentes y claros para ser presentados a niños y niñas entre los tres y cinco años de edad, de igual forma los resultados indica que el 
instrumento midio de forma adecuada lo que se pretendía medir (Apéndice D). En cuanto a la entrevista sugestiva (B), en las tres dimensiones los resultados fueron igualmente significativamente altos, por lo tanto el instrumento es pertinente, coherente y claro en sus 10 ítems (Apéndice E).

Tabla 4.

Resultados validación por jueces, Coeficiente Alfa de Cronbach

\begin{tabular}{cccc}
\hline Tipo de Entrevista & Coherencia & Pertinencia & Claridad \\
\hline No Sugestiva (A) & 0,992 & 0,993 & 0,988 \\
Sugestiva (B) & 0,990 & 0,989 & 0,988 \\
\hline
\end{tabular}

Altamente confiable: $>0.85$; medianamente entre 0.60 y 0.85 ; no es confiable $<0.60$.

Los resultados anteriores indican que el instrumento es confiable para la recolección de información y para realizar el análisis que el presente estudio tiene por objetivo. De igual forma, es preciso e importante resaltar que, teniendo en cuenta las observaciones realizadas por los jueces al momento de evaluar el instrumento, se realizaron una serie de ajustes a éste, dichos ajustes fueron de tipo gramatical, orden y redacción para una mayor claridad y comprensión de las preguntas.

\section{Análisis de diferencias de medias entre grupos}

El presente análisis se dividirá en tres segmentos, en el primero se podrá observar las diferencias entre grupos por cada ítem del instrumento, estableciéndose los porcentajes de participantes que respondieron correctamente (Entrevista A) y los que fueron o no sugestionados (Entrevista B), posteriormente, se encontrará un análisis de las diferencias de medias entre los grupos de las mismas edades, y en el tercer segmento se presentan las diferencias de medias entre los grupos de la entrevista sugestiva. 
La tabla 5 presenta las medias encontradas por ítem y por grupo, en cuánto al porcentaje de participantes que respondieron correctamente de acuerdo con el contenido de la obra y el porcentaje de niños y niñas que fueron sugestionados.

Tabla 5

Medias encontradas por ítem y por grupo (comparativo y experimental)

\begin{tabular}{|c|c|c|c|c|c|c|}
\hline Ítem & Entrevista & Edad & Media & Entrevista & Edad & Media \\
\hline \multirow{4}{*}{1} & & 3 años & 0,40 & \multirow{4}{*}{ Sugestiva (B) } & 3 años & 0,40 \\
\hline & No & 4 años & 0,67 & & 4 años & 0,50 \\
\hline & Sugestiva (A) & 5 años & 1,00 & & 5 años & 0,80 \\
\hline & & Total & 0,71 & & Total & 0,56 \\
\hline \multirow{4}{*}{2} & & 3 años & 0,67 & \multirow{4}{*}{ Sugestiva (B) } & 3 años & 0,00 \\
\hline & No & 4 años & 1,00 & & 4 años & 0,40 \\
\hline & Sugestiva (A) & 5 años & 0,80 & & 5 años & 0,50 \\
\hline & & Total & 0,82 & & Total & 0,33 \\
\hline \multirow{4}{*}{3} & & 3 años & 0,80 & \multirow{4}{*}{$\begin{array}{l}\text { Sugestiva } \\
\text { (B) }\end{array}$} & 3 años & 0,33 \\
\hline & No & 4 años & 1,00 & & 4 años & 0,83 \\
\hline & Sugestiva (A) & 5 años & 0,75 & & 5 años & 0,83 \\
\hline & & Total & 0,86 & & Total & 0,67 \\
\hline \multirow{4}{*}{4} & & 3 años & 0,67 & \multirow{4}{*}{ Sugestiva (B) } & 3 años & 0,60 \\
\hline & No & 4 años & 1,00 & & 4 años & 0,17 \\
\hline & Sugestiva (A) & 5 años & 0,75 & & 5 años & 0,83 \\
\hline & & Total & 0,80 & & Total & 0,53 \\
\hline \multirow{4}{*}{5} & & 3 años & 0,33 & \multirow{4}{*}{ Sugestiva (B) } & 3 años & 0,20 \\
\hline & No & 4 años & 1,00 & & 4 años & 0,17 \\
\hline & Sugestiva (A) & 5 años & 0,33 & & 5 años & 0,33 \\
\hline & & Total & 0,43 & & Total & 0,24 \\
\hline \multirow{4}{*}{6} & & 3 años & 0,00 & \multirow{4}{*}{ Sugestiva (B) } & 3 años & 0,25 \\
\hline & No & 4 años & 1,00 & & 4 años & 0,17 \\
\hline & Sugestiva (A) & 5 años & 1,00 & & 5 años & 0,67 \\
\hline & & Total & 0,33 & & Total & 0,31 \\
\hline \multirow{4}{*}{7} & & 3 años & 0,75 & \multirow{4}{*}{ Sugestiva (B) } & 3 años & 0,33 \\
\hline & No & 4 años & 1,00 & & 4 años & 0,00 \\
\hline & Sugestiva (A) & 5 años & 1,00 & & 5 años & 0,50 \\
\hline & & Total & 0,92 & & Total & 0,27 \\
\hline \multirow{4}{*}{8} & & 3 años & 0,60 & \multirow{4}{*}{ Sugestiva (B) } & 3 años & 0,33 \\
\hline & No & 4 años & 0,47 & & 4 años & 0,40 \\
\hline & Sugestiva (A) & 5 años & 0,75 & & 5 años & 0,83 \\
\hline & & Total & 0,57 & & Total & 0,53 \\
\hline
\end{tabular}




\begin{tabular}{|c|c|c|c|c|c|c|}
\hline \multirow{4}{*}{9} & \multirow{4}{*}{$\begin{array}{c}\text { No } \\
\text { Sugestiva (A) }\end{array}$} & 3 años & 0,50 & \multirow{4}{*}{ Sugestiva (B) } & 3 años & 0,00 \\
\hline & & 4 años & 0,75 & & 4 años & 0,25 \\
\hline & & 5 años & 1,00 & & 5 años & 0,50 \\
\hline & & Total & 0,75 & & Total & 0,29 \\
\hline
\end{tabular}

Para observar las tablas completas y gráficos de perfil Ver Apéndices F-N

Como se puede observar en la tabla 5, en el ítem 1, el $71 \%$ de los participantes de la entrevista no sugestiva (A), respondieron correctamente a las preguntas de acuerdo con el contenido de la obra, siendo los niños de cinco años quienes contestaron la totalidad de las pregunta con aciertos, en tanto, el 56\% de los participantes de la entrevista sugestiva (B), contestaron correctamente a las preguntas, lo que indica que el $44 \%$ restante dieron respuestas de acuerdo a lo que ocurrió en la obra, no se presenta gran diferencia entre los dos grupos (A y B) teniendo en cuenta que esta era una pregunta de control, para los dos grupos se aplico la misma.

Para el ítem 2, se encontró que el $82 \%$ de los participantes de la entrevista A contestaron correctamente a las preguntas, mientras que en la entrevista B sólo el 33\% contestó, siendo los niños de tres años los que más se dejaron sugestionar. En el ítem 3, en la entrevista A, el 86\% contestó de acuerdo al contenido de la obra, mientras que en la entrevista B fue del 67\%, siendo esta una de las preguntas dónde menos sugestionabilidad se presentó.

El análisis del ítem 4 arrojó que, en la entrevista A, el 80\% de los participantes contestaron correctamente a la pregunta, mientras que los participantes de la entrevista B, el 53\% contestó correctamente, el $47 \%$ restante se dejo sugestionar, y fueron los niños de 4 años los más sugestionables (83\%) seguidos por los de 3 años (40\%).

Las respuestas correctas en la entrevista A en los ítems 5 y 6, disminuyeron de forma considerable, $43 \%$ y $33 \%$, respectivamente, esto puede ser debido a que hubo una cantidad mayor de niños que respondieron que no recordaban la respuesta o simplemente no la contestaron. En la entrevista B, los porcentajes de sugestionabilidad empiezan a ser mayores, 
$76 \%$ y $69 \%$ (ítems 5 y 6 respectivamente), siendo los niños de 3 y 4 años quienes más respondieron a la sugestión buscada o pretendida por los investigadores.

En la entrevista A, y con referencia al ítem 7, se encontró que éste presenta el mayor porcentaje de respuestas correctas $(92 \%)$ de todo el instrumento, puesto que la totalidad de los niños de 4 y 5 años respondieron en correctamente al ítem, sin embargo, en la entrevista B se encontró uno de los porcentajes más bajos (27\%) de respuestas correctas, lo que indica que el $63 \%$ de los participantes fueron susceptibles a la sugestión.

Con respecto a los ítems 8 y 9, se encontró que, en la entrevista A, los porcentajes de respuesta correctas fueron $57 \%$ y $75 \%$ respectivamente. En el ítem 8 , el porcentaje fue considerablemente menor en comparación con los otros ítems, sobre todo en los participantes de 4 años, puesto que la mayoría de ellos mencionaron no recordar la respuesta o no dieron respuesta alguna. En la entrevista $\mathrm{B}$, los porcentajes de niños que fueron susceptibles a la sugestión fue, en el ítem 8 del 67\% y en el ítem 9 del 71\%, valores significativamente altos. La sugestión se observa en mayores porcentajes en los niños de 3 y 4 años de edad.

La tabla 6 presenta la prueba de los efectos inter-sujetos, con la cual se busco determinar por cada ítem diferencias significativas teniendo en cuenta todos los grupos, el tipo de entrevista y las edades. Los resultados encontrados indican que, en el ítem 1 (pregunta de control) no se encontró diferencias significativas entre las entrevistas como tampoco entre las edades, éste resultado, en particular, es de suma importancia puesto que permite establecer que al no haber sugestión para los grupos de la entrevista B, las respuestas y los grupos son equivalente ante una misma pregunta. 
Tabla 6

Pruebas de efectos inter-sujetos

\begin{tabular}{|c|c|c|}
\hline Îtem & Origen & Significancia \\
\hline \multirow{2}{*}{1} & Entrevista & 0,065 \\
\hline & Edad & 0,876 \\
\hline \multirow{2}{*}{2} & Entrevista & 0,002 \\
\hline & Edad & 0,139 \\
\hline \multirow{2}{*}{3} & Entrevista & 0,231 \\
\hline & Edad & 0,162 \\
\hline \multirow{2}{*}{4} & Entrevista & 0,148 \\
\hline & Edad & 0,604 \\
\hline \multirow{2}{*}{5} & Entrevista & 0,199 \\
\hline & Edad & 0,612 \\
\hline \multirow{2}{*}{6} & Entrevista & 0,226 \\
\hline & Edad & 0,054 \\
\hline \multirow{2}{*}{7} & Entrevista & 0,001 \\
\hline & Edad & 0,346 \\
\hline \multirow{2}{*}{8} & Entrevista & 0,744 \\
\hline & Edad & 0,212 \\
\hline \multirow{2}{*}{9} & Entrevista & 0,011 \\
\hline & Edad & 0,089 \\
\hline
\end{tabular}

Valor-p $=0,05$. Para observar las tablas completas y gráficos de perfil Ver Apéndices

Con respecto a las entrevistas, los ítems 2, 7 y 9 arrojaron diferencias significativas entre los grupos, es decir, que en estos ítems hubo una mayor cantidad de niños que respondieron de acuerdo a la sugestión realizadas por los investigadores. En tanto en el ítem 6 se presentó una tendencia $(0,054)$ a diferencia significativa por edad, esto quiere decir que hubo un mayor número de niños entre los 3 y 4 años que respondieron de forma correcta a la pregunta de sugestión.

Es importante mencionar que en la tabla 6 no se puede observar diferencias significativas, estadísticamente hablando, por entrevista o por edad en la mayoría de los ítems, lo cual puede estar explicado por el tamaño pequeño de la muestra, además de las respuestas entregadas por alguno niños ("no recuerdo" o no responder) disminuyendo los datos a analizar. 
Teniendo en cuenta la totalidad de las respuestas para los dos tipos de entrevista, la tabla 7 presenta los porcentajes encontrados por grupos que contestaron de forma correcta a las preguntas, en este análisis se encontró que en la entrevista A, los niños de 4 años (88\%) seguidos por los niños de 5 años $(80 \%)$ fueron los que contestaron más preguntas de forma acertada, en tanto en la entrevista B, los niños de 5 años fueron los que menos se dejaron sugestionar (mayor número de preguntas acertadas), los niños de 3 y 4 años tuvieron porcentajes similares (33\% y $34 \%$ respuestas correctas, respectivamente) por lo que son los grupos más sugestionables. Con respecto a la prueba de efectos inter-sujetos se encontró un nivel de significancia de 0,001 por entrevista pero no por edad (Ver Apéndice K).

Los resultados que se muestran en la tabla 7 son congruentes con los resultados observados en la tabla 4 y 5 , en las cuales se presenta que en la entrevista $A$, son los niños de 4 y 5 años quienes responden de forma más acertada o correctamente a las preguntas, y que en la entrevista B, los niños de 3 y 4 años son los que contestan menos preguntas de forma acertada y por lo tanto fueron más sugestionables.

Tabla 7

Estadísticos descriptivos, total de las respuestas por tipo de entrevista y grupos

\begin{tabular}{ccccc}
\hline Entrevista & Edad & Media & $\begin{array}{c}\text { Desviación } \\
\text { estándar }\end{array}$ & $\mathrm{N}$ \\
\hline \multirow{3}{*}{ No sugestiva (A) } & 3 años & 0,6403 & 0,27439 & 6 \\
& 4 años & 0,8889 & 0,13608 & 6 \\
& 5 años & 0,7996 & 0,19024 & 6 \\
& Total & 0,7763 & 0,22233 & 18 \\
\hline \multirow{2}{*}{ Sugestiva (B) } & 3 años & 0,3393 & 0,30115 & 6 \\
& 4 años & 0,3482 & 0,26601 & 6 \\
& 5 años & 0,6389 & 0,34418 & 6 \\
& Total & 0,4421 & 0,32068 & 18 \\
\hline \multirow{6}{*}{ Total } & 3 años & 0,4898 & 0,31647 & 12 \\
& 4 años & 0,6186 & 0,34685 & 12 \\
& 5 años & 0,7192 & 0,27810 & 12 \\
& Total & 0,6092 & 0,32042 & 36 \\
\hline
\end{tabular}


En cuanto a las diferencias por grupos y con base en los datos de la tabla 6, se realizó el siguiente análisis intra-grupos (3A-3B; 4A-4B; 5A-5B):

1. Grupos 3A-3B: el porcentaje de respuestas totales correctas fue del $64 \%$ versus el $34 \%$, respectivamente, por lo que la tasa o porcentaje de respuestas sugestionadas en el grupo 3B fue del $66 \%$.

2. Grupos 4A-4B: el porcentaje de respuestas totales correctas fue de $89 \%$ versus el $35 \%$, por lo que la tasa o porcentaje de respuestas sugestionadas en el grupo de $4 \mathrm{~B}$ fue del $65 \%$.

3. 5A-5B: el porcentaje de respuestas totales correctas fue de $80 \%$ versus el $64 \%$, por lo que la tasa o porcentaje de respuestas sugestionadas en el grupo de 5B fue del $36 \%$, considerablemente menor en comparación con los grupos 3B y $4 \mathrm{~B}$.

\section{Análisis pregunta No. 10}

Teniendo en cuenta que la pregunta número 10, en cada una de las entrevistas, era la narración libre por parte del niño de lo sucedido en la obra, se establecieron categorías que permitieron reunir las respuestas entregadas. El análisis de la pregunta se presentará por los grupos establecidos en el apartado de participantes y teniendo en cuenta el tipo de entrevista.

La tabla 8 presenta las respuestas entregadas por los participantes del grupo A (niños de 3 a 3,11 años de edad). Se encontró que, en el grupo comparativo (entrevista no sugestiva) el número de niños que no recordaron o dieron información poco coherente fue el mismo de aquellos niños que dieron una información corta pero con algunos aspectos importantes de la obra o hicieron una narración más completa. En tanto en el grupo experimental (entrevista sugestiva) las respuestas se concentraron en las categorías 1 y 2 , por lo que se puede evidenciar una posible confusión entre los hechos reales de la obra y los sugeridos en la entrevista. 
En la tabla 9 se puede observar las respuestas de los participantes del grupo B (niños de 4 a 4,11 años de edad), los resultados indican que tanto en el grupo comparativo y experimental, las respuestas se concentraron en las categorías 1 (No responde/No recuerda) y 2 (dieron respuestas cortas sin coherencia y/o mínima información), por lo tanto no se puede establecer con certeza si las respuestas en el grupo experimental estuvieron guiadas por la entrevista sugestiva.

Tabla 8

Respuestas de los participantes del grupo tres años - pregunta 10

\begin{tabular}{lcc}
\hline \multicolumn{1}{c}{ Categorías de Respuesta } & No Sugestiva & Sugestiva \\
\hline No responde/No recuerda & 1 & 2 \\
Respuestas cortas, poco coherentes y/o poco informativas & 2 & 4 \\
Respuestas cortas, pero con ideas principales de la obra & 2 & 0 \\
Narración de los aspectos más importantes de la obra & 1 & 0 \\
\hline
\end{tabular}

Tabla 9

Respuestas de los participantes del grupo cuatro años a la pregunta 10

\begin{tabular}{lcr}
\hline \multicolumn{1}{c}{ Categorías de Respuesta } & No Sugestiva & Sugestiva \\
\hline No responde/No recuerda & 4 & 3 \\
Respuestas cortas, poco coherentes y/o poco informativas & 2 & 2 \\
Respuestas cortas, pero con ideas principales de la obra & 0 & 1 \\
Narración de los aspectos más importantes de la obra & 0 & 0 \\
\hline
\end{tabular}

Las respuestas de los participantes del grupo C (niños de 5 a 5,11 años de edad), se pueden observar en la tabla 10 que, en el grupo comparativo el número de niños que no recordaron o dieron información poco coherente fue el mismo de aquellos niños que dieron una información corta pero con algunos aspectos importantes de la obra o hicieron una narración más completa. Con respecto al grupo experimental, se encontró que las respuestas se concentraron en las categorías 2 y 3 , evidenciándose una clara confusión entre los hechos reales de la obra. 
Tabla 10

Respuestas de los participantes del grupo cinco años a la pregunta 10

\begin{tabular}{lcc}
\hline \multicolumn{1}{c}{ Categorías de Respuesta } & No Sugestiva & Sugestiva \\
\hline No responde/No recuerda & 2 & 0 \\
Respuestas cortas, poco coherentes y/o poco informativas & 1 & 5 \\
Respuestas cortas, pero con ideas principales de la obra & 1 & 1 \\
Narración de los aspectos más importantes de la obra & 2 & 0 \\
\hline
\end{tabular}

\section{Análisis observaciones conductuales.}

Durante el desarrollo de las entrevistas se realizó un registro de aquellos indicadores (actitudes o comportamiento) que sugiriesen una alta o baja disponibilidad, motivación y/o atención del participante al momento de tener que contestar las preguntas sobre la obra de títeres. Estos indicadores pudieron haber influido en el desarrollo de la entrevista y/o en las respuestas entregadas por los participantes. Para el análisis de las observaciones conductuales se presentarán las más representativas en este tipo de actividad.

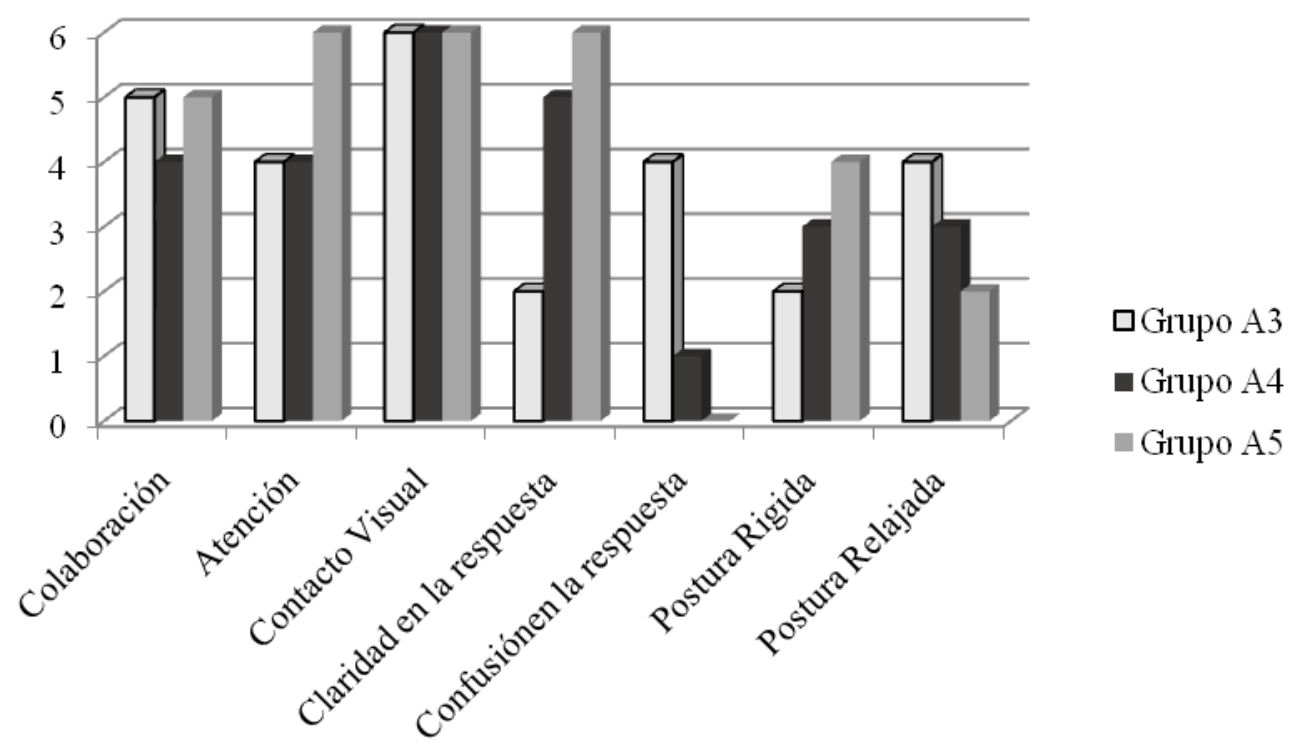

Figura 1. Observaciones conductuales destacadas en los grupos de la entrevista A. 
La figura 1 presenta los indicadores por grupos de la entrevista A (no sugestiva), encontrándose que en términos de colaboración, atención y contacto visual los tres grupos de edades tuvieron valores similares, es decir, la mayoría de los niños en las tres categorías estuvieron concentrados y trataron de mantener una actitud colaboradora.

En cuanto a la claridad o confusión al momento de responder, los niños de tres años fueron los que presentaron una mayor confusión mientras que los niños de cinco años tuvieron una mayor claridad. En cuanto al tipo de postura, de forma antagónica se encontró que fueron los niños de tres años quienes tuvieron una postura más relajada mientras que los niños de cinco años presentaron una postura más rígida.

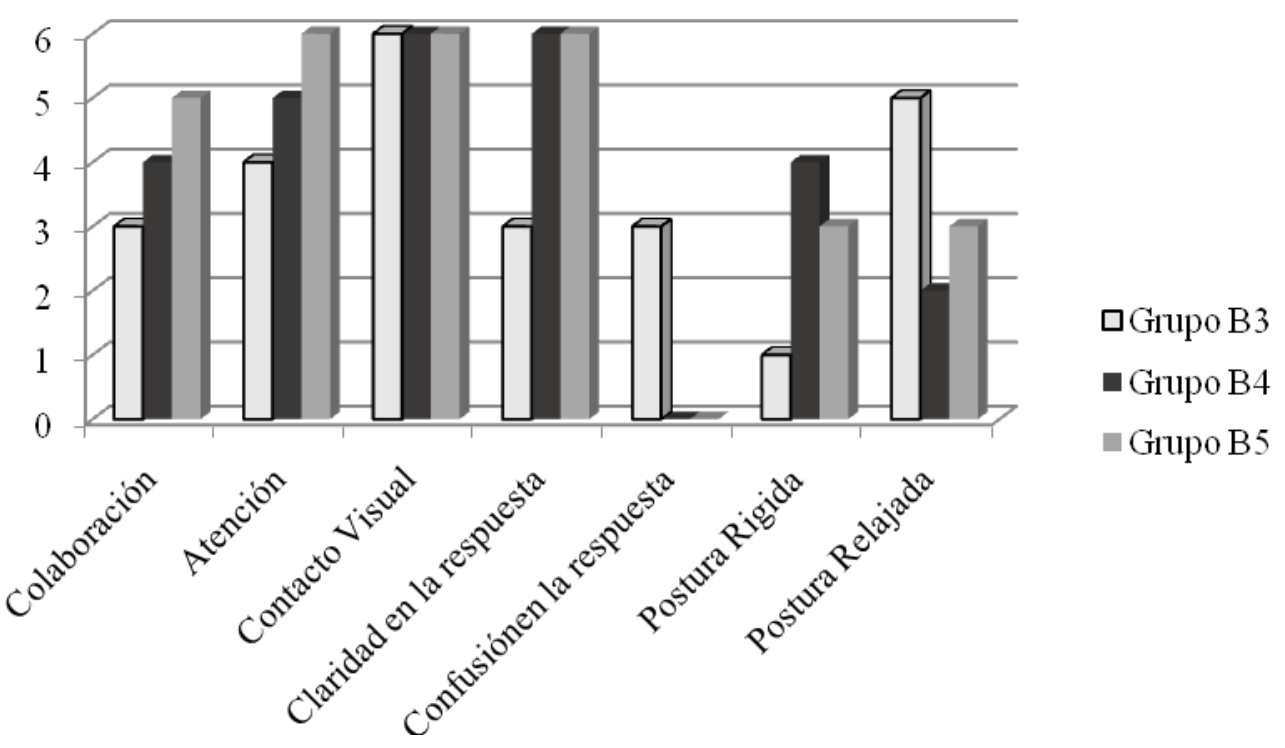

Figura 2. Observaciones conductuales destacadas en los grupos de la entrevista B.

Con respecto a los indicadores de la entrevista B (sugestiva), en la figura 2 se puede observar que en cuanto a la colaboración y atención el grupo de tres años fue el que registró la 
distribución más baja, mientras que en el contacto visual los tres grupos de edades tuvieron distribuciones similares.

Para los indicadores de claridad o confusión al momento de responder, los niños de tres años fueron los que presentaron una mayor confusión al momento de responder mientras que los niños de cuatro y cinco años, en su totalidad tuvieron una mayor claridad. Respecto a la postura, al igual que en los niños de tres años de la entrevista A, el grupo de tres años fueron quienes tuvieron una postura más relajada mientras que los niños de cuatro y cinco años presentaron una postura más rígida. 


\section{Discusión}

El objetivo del presente estudio fue comparar si existen diferencias en los recuerdos en relación con la actividad (obra de títeres) presentada a niños y niñas de 3 a 5 años, a partir de una entrevista con preguntas sugestivas y de una entrevista con preguntas no sugestivas, con sus correspondientes objetivos específicos de medir los tipos de recuerdos que se generen en cada uno de los participantes; medir en los grupos de estudio los recuerdos generados a través de la entrevista con preguntas sugestivas y entrevista con preguntas no sugestivas; y establecer la implantación de falsas memorias de los hechos vividos.

Para este propósito se diseñaron dos entrevistas (entrevista A con preguntas no sugestivas y entrevista B con preguntas sugestiva) que fueron sometidas a una validación por jueces expertos, este procedimiento permitió establecer la idoneidad, coherencia y pertinencia del instrumento en relación con la actividad.

Los resultados de la validación por jueces (coeficiente alfa de Chronbach) indicaron que para las tres dimensiones evaluadas: coherencia, pertinencia y claridad, los valores fueron significativamente altos (> 0.985) para los dos tipos de entrevistas. Si bien al instrumento se le hicieron cambios gramaticales, de redacción y orden de las preguntas, el instrumento cumple su objetivo, permitiendo recolectar la información necesitada.

De acuerdo con Goodman, Rudy, Bottons y Aman (1990, citados por Juárez y Salas, 2011) el recuerdo de un niño de 3 años, en una situación normal, puede ser bastante exacto, pero a medida que la edad va aumentando puede llegar a ser menos minucioso que el de un niño de 8 años, teniendo en cuenta lo anterior y en contraste con los resultados del presente estudio, en la entrevista A (con preguntas no sugestivas), con excepción de los ítems 5, 6 y 8, los niños de las diferentes edades evaluadas respondieron en cada ítem con más del $75 \%$ de respuestas correctas 
o acordes con el contenido de la obra, siendo los niños de cuatro y cinco años quienes presentaron un mayor índice de respuestas correctas.

En cuanto a lo anterior y con respecto a la entrevista B (con preguntas sugestivas), los porcentajes de respuestas correctas indican que en la mayoría de los ítems fue significativamente inferior en comparación con los participantes de la entrevista A, por lo que se puede establecer que en la entrevista sugestiva (B) los participantes fueron sugestionados, especialmente los niños de 3 años, implantando falsas memorias en cuanto a situaciones especificas de la obra de títeres. En este sentido los resultados del estudio reafirman los postulados de Miramontes, Stein y Mojardín, (2010 y Roediger y MacDermott, 1996, citados por García-Bajos y Migueles, 1998), quienes consideran que las falsas memorias son reportes memorísticos que difieren parcial o totalmente de los eventos experimentados o que se recuerdan hechos que no han ocurrido o recordarlos de forma diferente a como sucedieron, en este caso, los resultados permitieron determinar que los recuerdos de los niños sugestionados difirieron de forma parcial con lo hechos reales de la obra.

Con lo anterior se confirmaron las hipótesis de trabajo 1, 2 y 3 en las que se plantearon que existen diferencias en los recuerdos de niños de 3 a 5 años de edad, que han sido expuestos a una actividad lúdica, a partir del tipo de entrevista.

Con respecto al ítem 1 (pregunta de control) no hubo diferencias significativas entre los tipos de entrevista, aspecto importante puesto que permite establecer que sin sugestión los grupos tienen porcentajes de respuestas similares, sobre todo los niños de tres años, de igual forma en la prueba de efectos inter-sujetos (tabla 6) no existieron diferencias significativas ni por tipo de entrevista ni por grupos de edades. 
En los resultados de las pruebas de efectos inter-sujetos, se encontró que los ítems 2, 7 y 9 presentaron diferencias significativas en cuanto al tipo de entrevista, por lo que hubo una mayor cantidad de niños que respondieron de acuerdo a la sugestión realizada por los investigadores, en este aspecto, Pinchanski-Fachler, Víquez-Hidalgo y Zeledón-Grande (2004) y MojardínHeráldez (2007) consideran que, y acorde con lo realizado para los participantes de la entrevista B, las falsas memorias implantadas resultan de la exposición de una persona a información engañosa e incorporación de la misma a su repertorio de conocimiento. En este caso también se confirman las hipótesis de trabajo 1, 2 y 3, planteadas en párrafos anteriores.

En lo expuesto por los anteriores autores y en contraste con lo realizado en la investigación, a los participantes de la entrevista B, cuándo se les hacían preguntas sugestivas con respecto al contenido de la obra, éstos entregaron respuestas, sobre todo los niños de tres años, acordes a lo sugerido, situación que también se puede presentar en un interrogatorio policial o judicial, en el cuál se realizan comentarios o preguntas sugerentes, trayendo como consecuencia la alteración de la estructura y contenidos de los recuerdos y con ello los comportamientos, con consecuencias contraproducentes y graves para las personas acusadas falsamente Ceci y Bruck, (1995, citado por Mojardín-Heráldez, 2007).

La actividad realizada (obra de títeres) fue planificada y organizada, con un contenido educativo y dinámico en el que se hizo a los niños participes. Teniendo en cuenta que la actividad fue controlada, al tomar la sumatoria de todos los ítems (por todos los grupos), de cada instrumento, se encontró que el porcentaje total de respuestas correctas en la entrevista A (con preguntas sugestivas) fue del 78\% mientras que en la entrevista B (con preguntas sugestivas) fue del $44 \%$, por lo que se puede observar diferencias significativas entre el tipo de entrevista. Con esto se afirman las hipótesis de trabajo 1,2 y 3. 
De acuerdo a lo anterior, y ante estudios realizados en situación de laboratorio, Christianson y Hübinette 1993; y Yuille y Cutshall, (1986, citados por García-Bajos y Migueles, 1999) indican que, comparando entre sujetos que hayan sido estudiados bajo una situación en la que la emoción estuvo implícita y sujetos estudiados en situaciones neutras o de laboratorio, los primeros presentan mayores recuerdos detallados y precisos del suceso, son menos propensos o susceptibles a preguntas engañosas y presentan, en el tiempo, un mantenimiento claro de la información, por lo que los participantes (entrevista B) al estar expuestos a una situación planificada, organizada y controlada, fueron más susceptibles a la sugestión.

Teniendo en cuenta la actividad realizada en la investigación y la entrevista B con preguntas sugestivas, al momento de inducir o sugerir respuestas en los niños de las diferentes edades, se insistió para que los niños recordarán los hechos y cuando el participante expresaba que no recordaba o no tenía claridad de la respuesta, los investigadores lo animaban a confiar en sus recuerdos, de esta forma, se cumplieron con dos de los tres factores externos, postulados por Loftus (1997), que deben estar presentes para la creación o implantación de una falsa memoria, como son: se dan exigencias sociales para que los individuos recuerden algún hecho; y los sujetos pueden ser animados a no juzgar si sus construcciones son reales o no.

En términos generales, comparando y teniendo en cuenta los resultados de la entrevista B, se encontró que en el grupo de tres años, el porcentaje de respuestas sugestionadas fue del 66\%, en este mismo orden, en el grupo 4B la tasa o porcentaje de sugestión fue del $65 \%$ y en los niños del grupo 5B fue del 36\%, estos hallazgos concuerdan con los de dos estudios realizados por Goodman y Reed (1986) y Goodman et al. (2006) en los cuales después de una actividad le realizaron a los niños preguntas abiertas y sugestivas, encontrando que los menores entre los tres y cuatro años eran más sugestionables que los de cinco a seis años, indicando que ambos grupos 
se acercan al $100 \%$ de precisión cuando responden a preguntas cerradas y concisas como por ejemplo "¿esa persona te besó?", "¿esa persona te pegó?".

Con lo anterior, se confirman las hipótesis de trabajo 4, 5 y 6, en las que se planteaban que existen diferencias en los recuerdos de los niños del grupo A (3 a 3,11 años de edad), que han sido expuestos a una actividad lúdica, a partir del tipo de entrevista, con los niños del grupo B (4 a 4,11 años de edad), que han sido expuestos a una actividad lúdica, a partir del tipo de entrevista. Existen diferencias en los recuerdos de niños del grupo A (3 a 3,11 años de edad), que han sido expuestos a una actividad lúdica, a partir del tipo de entrevista con los niños del grupo C (5 a 5,11 años de edad), que han sido expuestos a una actividad lúdica, a partir del tipo de entrevista; y existen diferencias en los recuerdos de niños del grupo de B (4 a 4,11años de edad), que han sido expuestos a una actividad lúdica, a partir del tipo de entrevista con los niños del grupo C (5 a 5,11 años de edad), que han sido expuestos a una actividad lúdica, a partir del tipo de entrevista.

Con respecto a los resultados de la pregunta No. 10, se encontró que en los niños de tres años en la entrevista B el no recordar o dar respuestas poco coherentes y/o poco informativas fueron las categorías con mayor número de participantes, similares resultados se obtuvieron en los participantes de cuatro años, y en los participantes de cinco años la mayoría de respuestas fueron cortas e insuficientemente informativas y otros dieron respuestas cortas con ideas principales de la obra.

De acuerdo a los resultados anteriores, Mojardín-Heráldez (2008) y Reed y Ellis (2007), mencionan que en ocasiones las falsas memorias se presentan como pequeñas desviaciones de forma, es decir, cambiar características de una situación vivida, en este sentido, los resultados encontrados indicaron que los niños, en mayor frecuencia los de tres años en la entrevista B, 
confundían o cambiaban los nombres a los personajes, características puntuales de la obra, los sucesos en la línea de tiempo ó inclusive llegaron a informar de sucesos que no estaban presentes en la obra.

Los hallazgos de este estudio sirven de aporte a la psicología del testimonio, por cuanto permiten establecer la importancia de la clase de entrevista utilizada para la obtención y exactitud de la información de niños entre los 3 y 5 años de edad. Es así, que con la entrevista sin preguntas sugestivas se logra una mayor exactitud de los hechos recordados, mientras que con la entrevista con preguntas sugestivas, en un buen porcentaje, se presenta la implantación de falsas memorias. De igual manera, los resultados de esta investigación pueden ser de gran utilidad en los ambientes judiciales o forenses, en los cuales, en ciertas oportunidades, se investigan hechos (en algunos casos traumáticos) en los que tienen participación niños y niñas entre los 3 y 5 años de edad y de quienes se requiere de sus testimonios.

En este aspecto Espinosa (2011) y Querejeta (1999, citado por Luna y Migueles, 2007) consideran que en la psicología del testimonio al estudiar el testimonio de un adulto o niño en un proceso judicial, los factores que median en la exactitud del relato son de suma importancia, en este caso la memoria, la percepción y la atención son procesos fundamentales que permiten mantener o rememorar un recuerdo de lo ocurrido con mayor claridad, sin olvidar la importancia que reviste el tipo de entrevista que se utilice.

Por lo antes expuesto, es que investigaciones sobre el testimonio y la sugestión de éste, como se realizó en el presente estudio, para el ámbito jurídico, el testimonio de una víctima, testigo de un delito o inclusive del mismo victimario, es uno de los aspectos más importantes a tenerse en cuenta al momento de tomar decisiones, en cuanto a imputaciones y/o condenas penales. Cuando se realizan los interrogatorios o entrevistas, es importante que la persona 
encargada tenga experticia en el tema, pero sobre todo que tenga conocimiento y claridad en el tipo de entrevista que se debe realizar y en el tipo de preguntas que se deben formular.

En el mismo sentido, Loftus (1975, citada por Manzanero, 2001) manifiesta que uno de los momentos más delicados en los que puede modificarse la memoria, en el caso de testigos, por información sugerida es cuando se toma la declaración, para lo cual, y con el objeto de obtener mayor cantidad de información posible, normalmente se recurre a la formulación de preguntas que proporcionen más información que un relato libre de lo sucedido. Como contrapartida, por el uso de esas preguntas sugestivas los declarantes al contestarlas cometen inexactitudes: errores de comisión.

Si bien, uno de los aspectos más importantes de una entrevista es el "rapport", es decir, cuando se logra la empatía entre el entrevistador y el entrevistado a fin de normalizar la situación, y los estados de ansiedad, desconfianza, malestar, entre otros estados o reacciones emocionales negativas, ocasionadas por la misma entrevista. En este caso, el entrevistador debe tener sumo cuidado con cierto tipo de expresiones que emite puesto que éstas, y de acuerdo a lo postulado por Bruck y Ceci (1999, citados por Juárez-López y Sala-Berga, 2011), pueden llegar a ser sugestivas, suponiendo un riesgo para la fiabilidad de la declaración del entrevistado (por ejemplo, "te preguntaré por una cosa muy importante", "no tienes que tener miedo de explicarlo", "te sentirás mejor cuando lo expliques").

Con respecto al rapport y la presente investigación, al trabajarse con niños, los entrevistadores buscaron entablar una relación o comunicación empática y comprensiva, conversando, al inicio de la entrevista, de temas que llamaran su atención, para posteriormente entrar a hacer las preguntas respectivas del estudio. Los resultados indicaron que, la mayoría de los niños, independientemente de su edad, lograron relacionarse de forma positiva con el 
entrevistador, prestando atención y respondiendo a lo que se le preguntaba, hubo otros casos en los cuales los niños se demoraban o evitaban responder a las preguntas por no tener claridad de la respuesta.

El estudio permite establecer que, cuando se interrogan a menores de edad, sobre todo a niños entre los tres y los cinco años, que incluso puedan llegar a ser testigos o víctimas de un delito, quienes realicen las entrevistas deben tener claridad que si bien, los niños pueden tener una memoria excepcional, por su nivel de inmadurez y la posible relación de confianza que se establezca con quien realiza la entrevista, los niños tienden a ser más sugestionables, por lo que es imprescindible establecer métodos o tipos de herramientas con las cuáles la sugestión u otro tipo de factores que puedan influenciar en el testimonio del niño sean filtrados previniendo el sesgo en la entrevista.

En esta misma línea, Rodriguez, Serrano, Mayorga-Tobar y Palacios Pinzón, (2006), en un estudio sobre factores de distorsión testimonial en niños preescolares, encontraron que existe incidencia de la sugestionabilidad sobre el testimonio infantil, alterando la información original que debería ser reportada, debido a la presencia de un señuelo en las preguntas formuladas, lo que conlleva al menor a distorsionar sus respuestas. En la presente investigación de acuerdo con los resultados se encontró que los niños entre los 3 y 5 años de edad, participantes en la misma, al ser sometidos a una entrevista con preguntas sugestivas presentaron implantación de falsas memorias así: en niños de 3 años un porcentaje del $66 \%$, en niños de 4 años un 65\%; y en niños de 5 años en un $36 \%$.

Teniendo en cuenta los resultados obtenidos, las hipótesis de trabajo y los diferentes postulados teóricos y empíricos de estudios realizados en diversos países, se postula entonces que tanto el objetivo general como los específicos fueron alcanzados en su totalidad, indicando 
Implantación de falsas memorias en niños y niñas 65

que existen diferencias significativas al momento de establecerse una entrevista con preguntas sugestivas y una entrevista con preguntas no sugestivas, llevando, en el primer caso, a la implantación de falsas de memorias. 


\section{Conclusiones}

De acuerdo con los sustentos tanto teóricos como empíricos y con los resultados arrojados en la presente investigación, se puede concluir que:

1. Se cumplieron con los objetivos propuestos en la presente investigación.

2. Las hipótesis de trabajo fueron debidamente contrastadas y confirmadas. Con ello se evidencia que el tipo de entrevista que se aplique a los niños de 3 a 5 años influye en la exactitud y credibilidad del testimonio, siendo la entrevista con preguntas sugestivas la que arroja mayor probabilidad de implantación de falsas memorias.

3. Los resultados de la presente investigación revisten importancia en el ámbito forense, cuando los niños o niñas actúen dentro de los procesos judiciales ya sea con víctimas o testigos y de ellos se requiera un testimonio, para lo cual se debe tener en cuenta el tipo de entrevista a utilizar.

4. La sugestionabilidad influye en la distorsión del testimonio y ésta a su vez en el desenlace y decisión del proceso judicial.

5. Para lograr un buen rapport, en especial con niños y niñas de 3 años de edad por su desarrollo socio-afectivo, es necesario realizar acercamientos sucesivos del entrevistador con ellos a fin de lograr reconocimiento e interacción y obtener sus reportes verbales, por cuanto presentan mayor apego a sus cuidadores, en este caso con las profesoras del jardín, recordando que los niños y niñas son educados para no hablar con personas extrañas. Se llega a esta conclusión en atención a que 2 de los niños de 3 años de edad a los que el entrevistador formuló las preguntas no dieron respuesta alguna, sin embargo cuando la profesora los entrevistó emitieron las respuestas correspondientes, caso contrario a lo sucedido con los niños de 4 y 5 años. 
6. La prueba de pilotaje fue fundamental para el control de variables extrañas al momento de presentar la obra de títeres y aplicar las entrevistas a los participantes de la investigación. Control de variables en los resultados.

7. Con respecto a la pregunta 10 , el análisis realizado fue descriptivo y tuvo por objetivo establecer la fidelidad del relato de los sucesos de la obra por parte de los niños y niñas, estableciendo si existieron modificaciones, eliminación o invención de hechos de la obra, lo que permitió establecer las diferencias significativas entre los grupos, y la implantación de falsas memorias en los niños de los grupos de la entrevista B.

En desarrollo de la investigación se presentaron limitaciones, en los siguientes aspectos:

1. En la consecución de los participantes, niños y niñas entre los 3 y 5 años de edad, por la dificultad de encontrar un jardín infantil que acepte el desarrollo de esta clase de investigaciones, además de la renuencia de algunos padres para dar el consentimiento informado. Igual dificultad se presentó para la prueba de pilotaje.

2. En la obtención de un número significativo de niños y niñas entre los 3 y 5 años de edad, lo cual tiene repercusión en los resultados de la investigación.

3. En el desarrollo emocional y social de los niños y niñas de 3 años de edad, vocalización y poca empatía con ellos, por cuanto en las entrevistas, en algunos casos, no se logró su reporte verbal.

4. La realización de la entrevista con los niños y niñas de 3 años de edad conllevo más tiempo y dedicación, en comparación con los de 4 y 5 años.

5. Al momento de contestar a las preguntas o de relatar los sucesos de la obra, algunos niños y niñas hicieron relación con sus experiencias cotidianas que eran similares a las vividas 
por los personajes de la obra, dificultando así el obtener respuestas prontas y pertinentes de los niños y niñas.

6. La disponibilidad de todos los niños y niñas participantes para la presentación de la obra de títeres y posterior entrevista.

Siendo este un estudio visionario, puesto que en el país son pocos los estudios conocidos en el tema de las falsas memorias y una vez identificadas las limitaciones, se recomienda tener en cuenta:

1. Tamaño de la muestra: es importante que el número de participantes sea mayor al del estudio, para que el análisis estadístico tenga mayor impacto, y poder establecer la existencia de diferencias significativas más sólidas.

2. En futuras investigaciones sería pertinente que el tiempo en que se presente la obra y la entrevista a los niños y niñas sea más largo, por si se va a extrapolar al ámbito judicial, por cuanto el tiempo en que ocurren los hechos y el testimonio es bastante prolongado, tratando de llevar los aspectos del estudio a hechos más reales.

3. En atención a que en la presente investigación a los participantes se les mantuvo en una situación neutra y que por consideraciones éticas no se puede diseñar un ambiente traumático, sería importante realizar, en esta misma línea, investigaciones expo facto en niños que hayan vivido situaciones traumáticas, con el objeto de contrastar los resultados de este trabajo con los que arrojen futuras investigaciones.

4. De igual manera, se propone llevar a cabo investigación sobre falsas memorias relacionadas con falsos reconocimientos.

Los resultados de este estudio motivan seguir en la investigación de las falsas memorias, así como también el estudio o exploración de otras variables que puedan influir en la calidad del 
testimonio de una persona relacionada con un delito, estableciendo una visión más amplia y preocupada por desarrollar o establecer métodos eficientes que ayuden a establecer la exactitud y confiabilidad de un testimonio, sin influir en él, para así tener procesos judiciales enmarcados en la impartición de justicia verdadera. 


\section{Referencias}

Baddeley, A. (1998). Memoria Humana: Teoría y Práctica. Interamericana de España: McgrawHill /.

Bruck. M., y Ceci, S. (1999). The suggestibility of children's memory. Annual Review Psychology; 50: 419-439.

Cantón, J., y Cortés, M. (2008) Guía para la evaluación del abuso sexual infantil. España: Ediciones Pirámide.

Carrillo-Mora, P. (2010). Sistemas de memoria: reseña histórica, clasificación y conceptos actuales. Primera parte: Historia, taxonomía de la memoria, sistemas de memoria de largo plazo: memoria semántica. Salud Mental, 331: 85-93.

Dalla-Barba, G. (2005). Neuropsicología de la Falsa Memoria. Revista Argentina de Neuropsicología, 5: 2-14.

Echeburúa, E. y Guerricaechevarría, C. (2000). Abuso sexual en la infancia, víctimas y agresores. Un enfoque clínico. Barcelona: Ariel.

Espinosa, A. (2011). La psicología del testimonio. En Hernández (Eds.). Psicología Jurídica Iberoamericana (capitulo 8). Bogotá: Editorial El Manual Moderno.

García-Bajos, E., y Migueles, M. (1999). Memoria de testigos en una situación emocionales neutra. Psicológica, 20: 91-102.

Garrido, E., y Masip, J. (2004). La evaluación del abuso sexual. Ponencia presentada en el I Congreso de Psicología Jurídica y Forense en red (http://www.copmadrid.org/congresoredforense/). Universidad de Salamanca. 
Garrido, E., y Masip, J. (2008). La obtención de información mediante entrevista. En Garrido, E, Masip, J., y Herrero, M. (Eds.). Psicología Jurídica (capitulo 12). España: Editorial Pearson Prentice Hall.

Goodman, G. S. \& Reed, R. S. (1986). Age difference in eyewitness testimony. Law and Human Behavior, 10: 317-332.

Goodman, G. S., Myers, J. E., Qin, J., Quas, J. A., Castelli, P., Redlich, A. D., y Rogers, L. (2006). Hearsay versus children's testimony: Effects of truthful and deceptive statements on

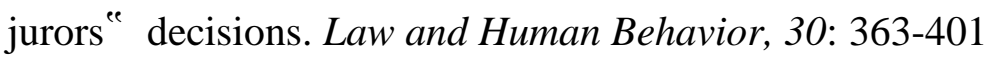

Gramunt-Fombuena, N. (2008). Normalización y validación de un test de memoria en envejecimiento normal, deterioro cognitivo leve y enfermedad de Alzheimer. Tesis Doctoral. Centre Facultat de Psicologia, Ciències de 1'Educació i de l'Esport. Universitat Ramón Llull.

Gutiérrez de Piñeres, C. (2010).Revisión sobre la definición de Psicología Jurídica. Revista Diversitas - Perspectivas en Psicología, 2 (6): 221-235

Hernández, C., y Roebers, C. (2007). Efectos de los incentivos en la regulación estratégica de los testimonios infantiles. Anuario de psicología, 3 (38): 413-430.

Hoffmeister-Torres, W. (2003). Trauma, memoria y el peritaje forense. Medicina legal de Costa Rica, 20 (2).

Ibabe, I (2008). Memorias recobradas y falsas memorias. En Garrido, E, Masip, J., y Herrero, M. (Eds.). Psicología Jurídica (capitulo 9). España: Editorial Pearson Prentice Hall.

Juárez-López, J., y Sala-Berga, E. (2011). Entrevistando a niños preescolares víctimas de abuso sexual y/o maltrato familiar. Eficacia de los modelos de entrevista forense. Centro de Estudios Jurídicos y Formación Especializada de Barcelona. 
Kazdin, AE. (1996). Modificación de la conducta y sus aplicaciones prácticas. México, D.F.: Editorial Manual Moderno.

King, A.(1994). Guiding knowledge construction in the classroom: effects of teaching children. How to question and how to explain. American Educational Research Journal, 31 (2): 338368.

Kolb, B., y Whishaw, I. (2006). Neuropsicología Humana. España: Editorial Médica Panamericana.

Lahey, B. (1999). Introducción a la psicología. Sexta edición. McGraw Hill: España.

Leichtman, M., y Ceci, S. (1995). The effects of stereotypes and suggestibility on prescholers reports. Developmental Journal; 3 (4): 568-578.

Ley 1090. (2006). Por la cual se reglamenta el ejercicio de la profesión de Psicología, se dicta el Código Deontológico y Bioético y otras disposiciones. Congreso de Colombia.

Loftus, E.F. (1997). Creating False Memories. Scientifi c American, 277 (3): 70-75.

Luna, K., y Migueles, M. (2007). Memorias de testigos: patrón de distorsión de los recuerdos por la presentación de información falsa. Eguzkilor, 21: 341-363.

Manzanero, A. (2002). Recuerdos reales y recuerdos sugeridos: características diferenciales. IV Congreso Iberoamericano de Psicología Jurídica. Madrid España: Defensor del menor de la Comunidad de Madrid. Pp 491-503.

Manzanero, A. (2008). Psicología del testimonio una aplicación de los estudios sobre la memoria. Madrid España: Ediciones Pirámide.

Manzanero, A. (2009). Análisis de contenido de memorias autobiográficas falsas. Anuario de psicología, 19: 61-72. 
Manzanero, A. (2010). Memoria de testigos obtención y valoración de la prueba testifical. Madrid: Ediciones Pirámide.

Masip, J, Garrido, E. (2007). La evaluación del abuso sexual infantil. España: Editorial Mad.

Merriman, W., Azmitia, M., y Perlmotter, M. (1988). Rate of forgetting in early childhood. International Journal of behavioral development, 11 (4): 467-474.

Miramontes, M.M., Stein, L.M., y Mojardín, A.H. (2010). ¿Puede el efecto de generación producir falsa memorias?. Acta Colombiana de Psicología; 2 (13): 175-184.

Mojardín-Heráldez, A. (2007). Psicología del testimonio: Falsas memorias espontáneas. Revista Psico-logos, 2: 39-49.

Mojardín-Heráldez, A. (2008). Origen y manifestaciones de las falsas memorias. Acta Colombiana de Psicología; 11 (19): 37-43.

Muñoz, J.M., Manzanero, A., Alcázar, M.A., González, J., Pérez, M. L., y Yela, M. (2011). Psicología Jurídica en España: Delimitación Conceptual, Campos de Investigación e Intervención y Propuesta Formativa dentro de la Enseñanza Oficial. Anuario de Psicología Jurídica; 21: 3-14

Pinchanski-Fachler, S., Víquez Hidalgo, M., y Zeledón Grande, C. (2004). Memorias impuestas.Medicina legal de Costa Rica; 21 (2).

Puente, A, (2005). Cognición y aprendizaje. Madrid España: Editorial Pirámide.

Reed, R., y Ellis, H. (2007). Fundamentos de Psicología cognitiva. México: Editorial Manual Moderno.

Rodriguez, M., Serrano, M., Mayorga-Tobar, M., y Palacios-Pinzón, A. (2006). Factores de distorsión testimonial en niños preescolares. Cuadernos Hispanoamericanos de Psicología, $7(1): 25-40$. 
Implantación de falsas memorias en niños y niñas 74

Sales, B., y Folkman, S. (2003). Ethics in Research with Human Participants. New York: Blackwell Publishing Ltd.

Tulving, E. (2002). Episodic memory: from mind to brain. Annual Review of Psychology; 53, 125 


\section{Apéndices}

\section{Apéndice A}

Formato de consentimiento informado

Bogotá, D.C.,

Yo , en mi calidad de padre madre presto voluntariamente

$\mathrm{mi}$ consentimiento para que $\mathrm{mi}$ hijo(a) , participe en una investigación a través de la cual se busca conocer con mayor profundidad cómo funciona la memoria de niños entre los 3 a los 6 años de edad. La investigación la están adelantando los psicólogos Ruth Rosalba Niño Castro y Jorge Enrique Acero Triviño, estudiantes de la Maestría de Psicología Jurídica de la Universidad Santo Tomás de Bogotá, bajo la asesoría de la Doctora Carolina Gutiérrez de Piñeres Botero, en el cual será entrevistado (a) por parte de los mencionados profesionales, luego de una actividad a cargo de las profesoras del jardín infantil donde se encuentra matriculado mi hijo (a).

De igual manera, autorizo la grabación en audio y/o video de la actividad que se lleve a cabo en el Jardín Infantil en la que participe mi hijo (a) y de la entrevista que se le realice, las cuales serán estrictamente confidenciales y con fines netamente académico-investigativos y en cuyo informe no aparecerá individualizado mi hijo (a) sino solamente en datos estadísticos.

Se me ha explicado que la investigación no representa ningún impacto negativo para mi hijo (a), y que mi hijo (a) no tendrá que responder ninguna pregunta si él o ella no quiere, además será el primer consultado (a) sobre el deseo de participar o no en la investigación, así mismo podrá retirarse en el momento que lo decida. 
Cuando se hayan analizado los resultados, se prepara un informe que será compartido con el jardín y con los padres que lo quieran conocer.

He recibido una información clara y completa del objeto del trabajo que adelantan los psicólogos, de la actividad y entrevista a realizarse y de la utilización de los audios y videos.

Hago constar que el presente documento, ha sido leído y comprendido por mí en su integridad por lo que en constancia firmo y acepto su contenido.

Autorizo,

Firma:

CC \#

Asentimiento,

Firma del niño

Les pedimos el favor de regresar este consentimiento informado antes del

dejándonos saber si su hijo (a) puede participar en esta investigación. Si tiene alguna pregunta o duda sobre el estudio puede comunicarse con nosotros por correo electrónico ruthminica@yahoo.com o a los celulares 3162366202 o 3112284378.

Gracias por su tiempo y consideración.

Cordialmente,

Ruth Rosalba Niño Castro Psicóloga Universidad de la Sabana
Jorge Enrique Acero Triviño

Psicólogo Universidad Católica de Colombia 


\section{Apéndice B}

Entrevista A

\section{INSTRUMENTO DE RECOLECCIÓN DE INFORMACIÓN IMPLANTACIÓN DE FALSAS MEMORIAS EN NIÑOS A TRAVÉS DE LA ENTREVISTA NO SUGESTIVA}

Participante: Femenino Masculino

Edad Cronológica:

Estrato: Nivel de Escolaridad:

Nombre del entrevistador:

Fecha de aplicación:

Instrucciones: Hola (nombre del niño/a), mi nombre es (nombre del entrevistador), me gustaría que habláramos sobre la obra de títeres que viste ayer, ¿podrías ayudarme a contestar unas preguntas? Gracias.

\begin{tabular}{|c|c|c|c|}
\hline PREGUNTAS & Acierto & $\begin{array}{c}\text { No } \\
\text { Acierto }\end{array}$ & $\begin{array}{l}\text { Observaciones } \\
\text { Conductuales }\end{array}$ \\
\hline $\begin{array}{l}\text { ¿En qué lugar estaban los títeres que } \\
\text { viste ayer? (Control). } \\
\text { Respuesta correcta: En el castillo, } \\
\text { parque, jardín infantil. }\end{array}$ & & & \\
\hline $\begin{array}{l}\text { ¿Para dónde se fue la vaquita? } \\
\text { Respuesta correcta: Al parque. }\end{array}$ & & & \\
\hline $\begin{array}{l}\text { ¿En qué iba el tigre a convertir a los } \\
\text { niños desobedientes? } \\
\text { Respuesta correcta: En perro caliente. }\end{array}$ & & & \\
\hline $\begin{array}{l}\text { ¿Qué canción canto la vaquita? } \\
\text { Respuesta correcta: Sol solecito. }\end{array}$ & & & \\
\hline $\begin{array}{l}\text { ¿Cómo se llamaba la vaquita? } \\
\text { Respuesta correcta: Para qué. }\end{array}$ & & & \\
\hline
\end{tabular}




\begin{tabular}{|c|c|c|c|}
\hline PREGUNTAS & Acierto & $\begin{array}{c}\text { No } \\
\text { Acierto }\end{array}$ & $\begin{array}{l}\text { Observaciones } \\
\text { Conductuales }\end{array}$ \\
\hline $\begin{array}{l}\text { ¿Qué llevaba el tigre en el cuello? } \\
\text { Respuesta correcta: una cinta roja. }\end{array}$ & & & \\
\hline $\begin{array}{l}\text { ¿Qué palabras mágicas dijo el mico } \\
\text { para convertir al tigre en bueno? } \\
\text { Respuesta correcta: Abra cadabra } \\
\text { patas de cabra. }\end{array}$ & & & \\
\hline $\begin{array}{l}\text { ¿Por qué el tigre se llevó a la vaquita? } \\
\text { Respuesta correcta: Por desobediente, } \\
\text { por ir sola al parque, porque no le hizo } \\
\text { caso a la mamá. }\end{array}$ & & & \\
\hline $\begin{array}{l}\text { ¿Qué te hizo prometer la vaquita? } \\
\text { Respuesta correcta: Portarme bien, } \\
\text { hacerle caso a mis papitos, tender la } \\
\text { cama, no ir solo al parque, hacer las } \\
\text { tareas, bañarme todos los días y querer } \\
\text { mucho a mis papitos. }\end{array}$ & & & \\
\hline
\end{tabular}

Pregunta 10. Por favor cuéntame todo lo que ocurrió en la obra de los títeres. (Control). 


\section{Apéndice C}

Entrevista B

\section{INSTRUMENTO DE RECOLECCIÓN DE INFORMACIÓN IMPLANTACIÓN DE FALSAS MEMORIAS EN NIÑOS A TRAVÉS DE LA ENTREVISTA SUGESTIVA}

Participante: Femenino Masculino

Edad Cronológica:

Estrato: Nivel de Escolaridad:

Nombre del entrevistador:

Fecha de aplicación:

Instrucciones: Hola (nombre del niño/a), mi nombre es (nombre del entrevistador), me gustaría que habláramos sobre la obra de títeres que viste ayer, ¿podrías ayudarme a contestar unas preguntas? Gracias.

\begin{tabular}{|c|c|c|c|}
\hline PREGUNTAS & Acierto & $\begin{array}{c}\text { No } \\
\text { Acierto }\end{array}$ & $\begin{array}{l}\text { Observaciones } \\
\text { Conductuales }\end{array}$ \\
\hline $\begin{array}{l}\text { ¿En qué lugar estaban los títeres que } \\
\text { viste ayer? (Control). } \\
\text { Respuesta correcta: En el castillo, } \\
\text { parque, jardín infantil. }\end{array}$ & & & \\
\hline $\begin{array}{l}\text { ¿La vaquita se fue a la casa de su } \\
\text { amiga? } \\
\text { Respuesta correcta: La vaquita no se } \\
\text { fue a la casa de su amiga. }\end{array}$ & & & \\
\hline $\begin{array}{l}\text { ¿El tigre dijo que a los niños los iba a } \\
\text { convertir en papas fritas? } \\
\text { Respuesta correcta: Los iba a } \\
\text { convertir en perros calientes. }\end{array}$ & & & \\
\hline $\begin{array}{l}\text { ¿La vaquita cantó los pollitos dicen pio } \\
\text { pio? } \\
\text { Respuesta correcta: Cantó Sol }\end{array}$ & & & \\
\hline
\end{tabular}




\begin{tabular}{|c|c|c|c|}
\hline PREGUNTAS & Acierto & $\begin{array}{c}\text { No } \\
\text { Acierto }\end{array}$ & $\begin{array}{l}\text { Observaciones } \\
\text { Conductuales }\end{array}$ \\
\hline solecito. & & & \\
\hline $\begin{array}{l}\text { ¿La mamá le puso a la vaquita el } \\
\text { nombre de Lola? } \\
\text { Respuesta correcta: El nombre de la } \\
\text { vaquita el PARA QUÉ. }\end{array}$ & & & \\
\hline $\begin{array}{l}\text { ¿De qué color era el sombrero que } \\
\text { llevaba el tigre? } \\
\text { Respuesta correcta: El tigre no } \\
\text { llevaba sombrero. }\end{array}$ & & & \\
\hline $\begin{array}{l}\text { ¿Qué palabras mágicas dijo el mico } \\
\text { para convertir al pollo en bueno? } \\
\text { Respuesta correcta: Fue el mico el } \\
\text { que utilizo palabras mágicas para } \\
\text { convertir al tigre en bueno, no existió } \\
\text { ningún pollo. }\end{array}$ & & & \\
\hline $\begin{array}{l}\text { ¿El tigre se llevó a la vaquita porque } \\
\text { grito a la profesora? } \\
\text { Respuesta correcta: Se la llevó por } \\
\text { desobediente, por ir sola al parque, } \\
\text { porque no le hizo caso a la mamá. }\end{array}$ & & & \\
\hline $\begin{array}{l}\text { ¿La vaquita te hizo prometer que irías } \\
\text { con tus papás al parque? } \\
\text { Respuesta correcta: La vaquita no } \\
\text { hizo esa promesa. }\end{array}$ & & & \\
\hline
\end{tabular}

Pregunta 10. Por favor cuéntame lo que ocurrió en la obra de los títeres. (Control). 


\section{Apéndice D}

\section{Confiabilidad: Coeficiente de Cronbach, Entrevista A.}

Coherencia

\begin{tabular}{cc}
\hline Alfa de Cronbach & No. de elementos \\
\hline 0,992 & 10 \\
& Pertinencia \\
\hline Alfa de Cronbach & No. de elementos \\
\hline 0,993 & 10 \\
\hline Alfa de Cronbach & \\
\hline 0,988 & Claridad \\
\hline & \\
\hline & \\
\hline & \\
\hline & \\
\hline
\end{tabular}




\section{Apéndice E}

\section{Confiabilidad: Coeficiente de Cronbach, Entrevista B.}

\begin{tabular}{cc} 
Coherencia \\
\hline Alfa de Cronbach & No. de elementos \\
\hline 0,990 & 10 \\
\hline & Pertinencia \\
\hline Alfa de Cronbach & No. de elementos \\
\hline 0,989 & 10 \\
\hline & \\
\hline & Claridad
\end{tabular}

\begin{tabular}{cc}
\hline Alfa de Cronbach & No. de elementos \\
\hline 0,988 & 10 \\
\hline
\end{tabular}




\section{Apéndice F}

\section{Análisis Ítem 1 por Entrevista y por Edad}

\section{Estadísticos descriptivos}

Variable dependiente: IT1

\begin{tabular}{clrrr}
\hline \multirow{2}{*}{ Entrevista } & Edad & Media & $\begin{array}{r}\text { Desviación } \\
\text { estándar }\end{array}$ & N \\
\hline \multirow{3}{*}{ No sugestiva (A) } & 3 años &, 40 &, 548 & 5 \\
& 4 años &, 67 &, 516 & 6 \\
& 5 años & 1,00 &, 000 & 6 \\
& Total &, 71 &, 470 & 17 \\
\hline \multirow{3}{*}{ Sugestiva (B) } & 3 años &, 40 &, 548 & 5 \\
& 4 años &, 50 &, 548 & 6 \\
& 5 años &, 80 &, 447 & 5 \\
Total & Total &, 56 &, 512 & 16 \\
& 3 años &, 40 &, 516 & 10 \\
& 4 años &, 58 &, 515 & 11 \\
& 5 años &, 91 &, 302 & 33 \\
\hline
\end{tabular}

Pruebas de efectos inter-sujetos

Variable dependiente: IT1

\begin{tabular}{lrrrrr}
\hline \multicolumn{1}{c}{ Origen } & $\begin{array}{r}\text { Tipo III } \\
\text { de suma de } \\
\text { cuadrados }\end{array}$ & gl & $\begin{array}{r}\text { Cuadrático } \\
\text { promedio }\end{array}$ & F & Sig. \\
\hline Modelo corregido & $1,603^{\text {a }}$ & 5 &, 321 & 1,435 &, 244 \\
Interceptación & 12,898 & 1 & 12,898 & 57,720 &, 000 \\
Entrevista &, 122 & 1 &, 122 &, 547 &, 466 \\
Edad & 1,350 & 2 &, 675 & 3,021 &, 065 \\
\hline$\quad$ Entrevista &, 060 & 2 &, 030 &, 133 &, 876 \\
$\quad$ Edad & 6,033 & 27 &, 223 & & \\
Error & 21,000 & 33 & & & \\
Total & 7,636 & 32 & & & \\
Total corregido & 210 & & & & \\
al cuadrado = 210 (R al cuadrado ajustada $=, 064)$ & & & &
\end{tabular}




\section{Gráficos de Perfil}

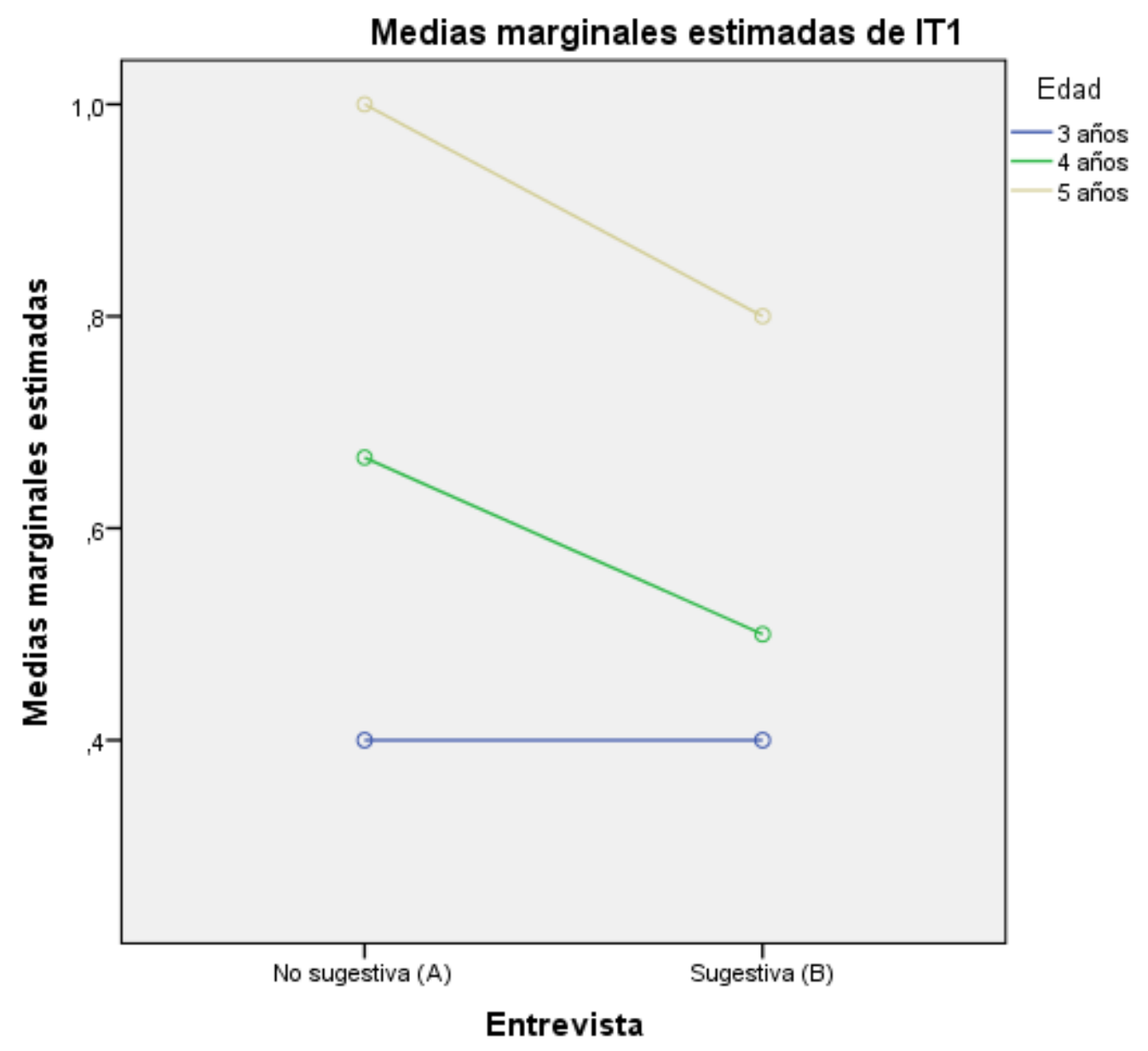




\section{Apéndice G}

\section{Análisis Ítem 2 por Entrevista y por Edad}

\section{Pruebas de efectos inter-sujetos}

Variable dependiente: IT2

\begin{tabular}{|c|c|c|c|c|c|}
\hline Origen & $\begin{array}{c}\text { Tipo III de } \\
\text { suma de } \\
\text { cuadrados }\end{array}$ & gl & $\begin{array}{c}\text { Cuadrático } \\
\text { promedio }\end{array}$ & $\mathrm{F}$ & Sig. \\
\hline Modelo corregido & $2,885^{\mathrm{a}}$ & 5 &, 577 & 3,104 &, 025 \\
\hline Interceptación & 9,856 & 1 & 9,856 & 53,019 & ,000 \\
\hline Entrevista & 2,134 & 1 & 2,134 & 11,481 & ,002 \\
\hline Edad &, 792 & 2 & ,396 & 2,130 & , 139 \\
\hline $\begin{array}{l}\text { Entrevista } * \\
\text { Edad }\end{array}$ & ,201 & 2 &, 100 &, 541 & ,589 \\
\hline Error & 4,833 & 26 & , 186 & & \\
\hline Total & 19,000 & 32 & & & \\
\hline Total corregido & 7,719 & 31 & & & \\
\hline
\end{tabular}

\section{Gráficos de perfil}

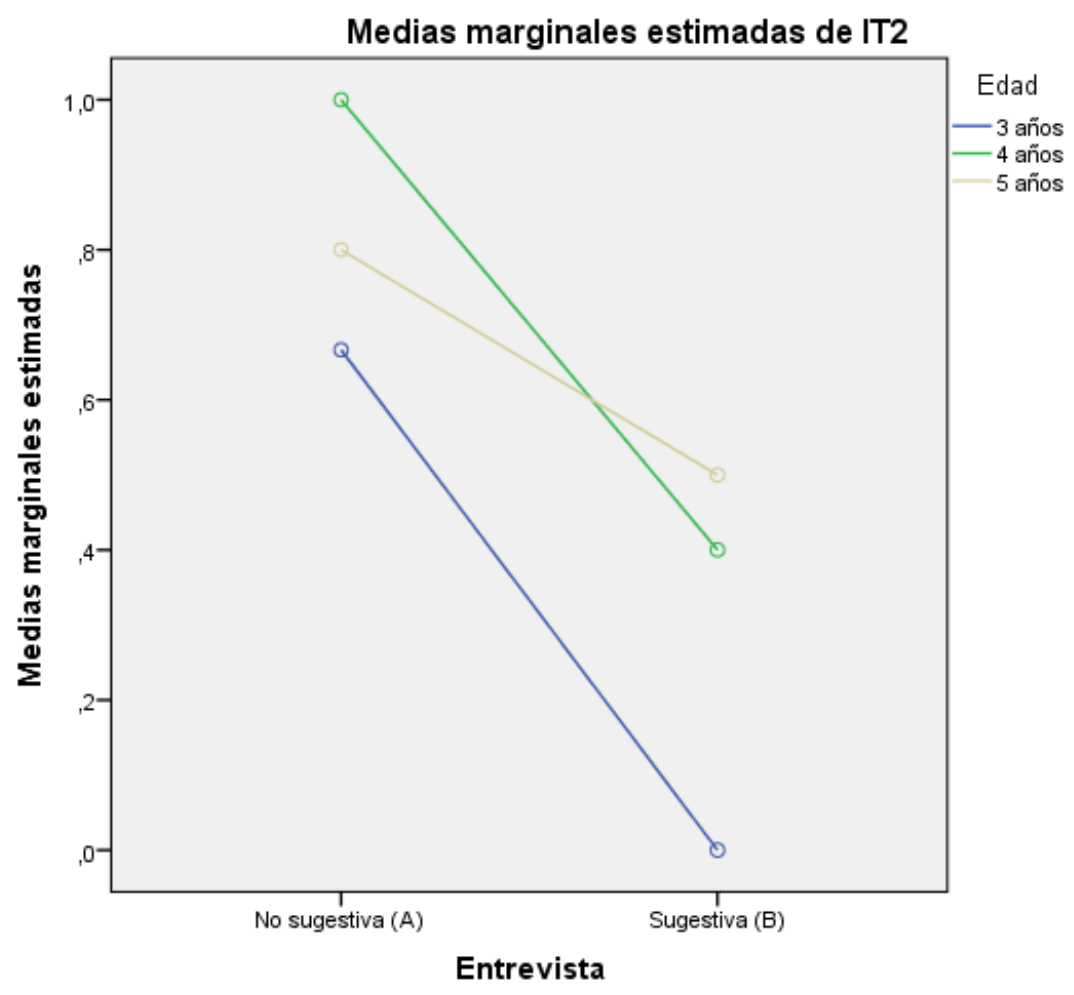




\section{Apéndice $\mathbf{H}$}

\section{Análisis Ítem 3 por Entrevista y por Edad}

\section{Pruebas de efectos inter-sujetos}

Variable dependiente: IT3

\begin{tabular}{|c|c|c|c|c|c|}
\hline Origen & $\begin{array}{l}\text { Tipo III de } \\
\text { suma de } \\
\text { cuadrados }\end{array}$ & gl & $\begin{array}{c}\text { Cuadrático } \\
\text { promedio }\end{array}$ & $\mathrm{F}$ & Sig. \\
\hline $\begin{array}{l}\text { Modelo } \\
\text { corregido }\end{array}$ & $1,450^{\mathrm{a}}$ & 5 & ,290 & 1,657 &, 180 \\
\hline Interceptación & 18,002 & 1 & 18,002 & 102,870 &, 000 \\
\hline Entrevista & ,263 & 1 & ,263 & 1,503 & ,231 \\
\hline Edad & ,685 & 2 & ,342 & 1,957 & , 162 \\
\hline $\begin{array}{l}\text { Entrevista } \\
\text { Edad }\end{array}$ & ,389 & 2 & ,195 & 1,113 & ,344 \\
\hline Error & 4,550 & 26 &, 175 & & \\
\hline Total & 24,000 & 32 & & & \\
\hline Total corregido & 6,000 & 31 & & & \\
\hline
\end{tabular}

\section{Gráficos de perfil}

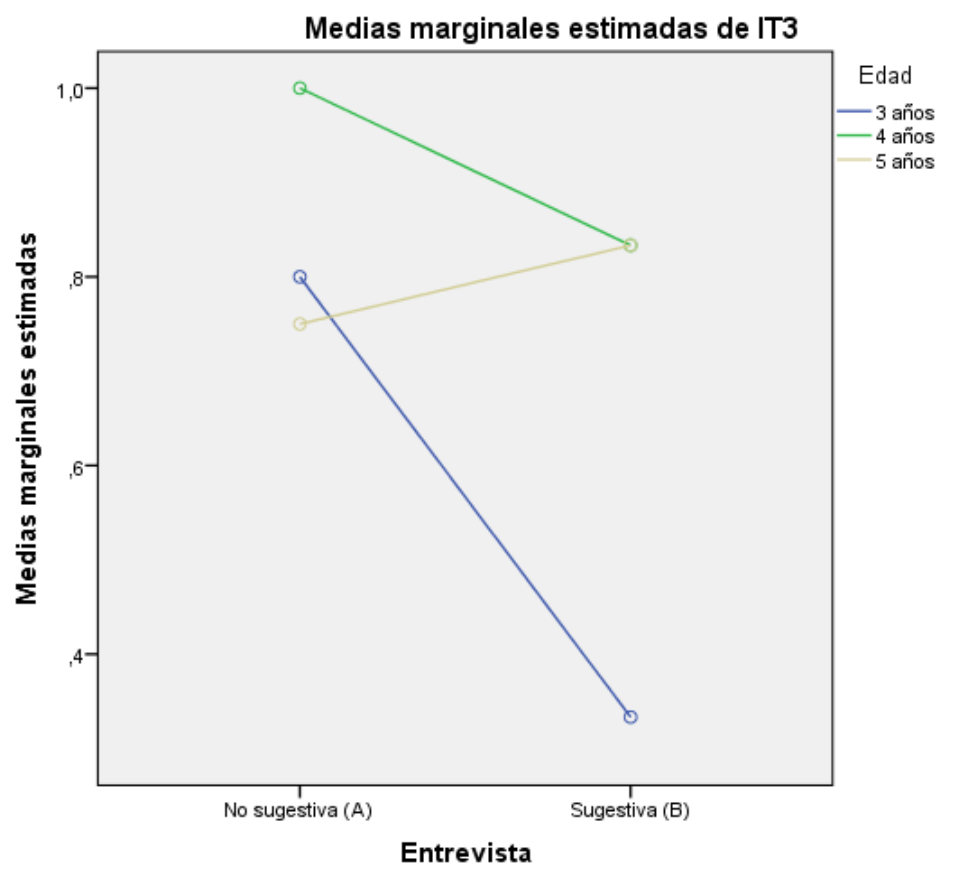




\section{Apéndice I}

\section{Análisis Ítem 4 por Entrevista y por Edad}

\section{Pruebas de efectos inter-sujetos}

Variable dependiente: IT4

\begin{tabular}{|c|c|c|c|c|c|}
\hline Origen & $\begin{array}{l}\text { Tipo III de } \\
\text { suma de } \\
\text { cuadrados }\end{array}$ & $\mathrm{gl}$ & $\begin{array}{c}\text { Cuadrático } \\
\text { promedio }\end{array}$ & $\mathrm{F}$ & Sig. \\
\hline $\begin{array}{l}\text { Modelo } \\
\text { corregido }\end{array}$ & $2,013^{\mathrm{a}}$ & 5 & ,403 & 1,974 &, 125 \\
\hline Interceptación & 11,127 & 1 & 11,127 & 54,551 &, 000 \\
\hline Entrevista & ,460 & 1 & ,460 & 2,255 &, 148 \\
\hline Edad &, 211 & 2 & , 105 &, 516 & ,604 \\
\hline $\begin{array}{l}\text { Entrevista } \\
* \text { Edad }\end{array}$ & 1,010 & 2 & ,505 & 2,476 &, 108 \\
\hline Error & 4,283 & 21 & ,204 & & \\
\hline Total & 17,000 & 27 & & & \\
\hline Total corregido & 6,296 & 26 & & & \\
\hline
\end{tabular}

\section{Gráficos de perfil}

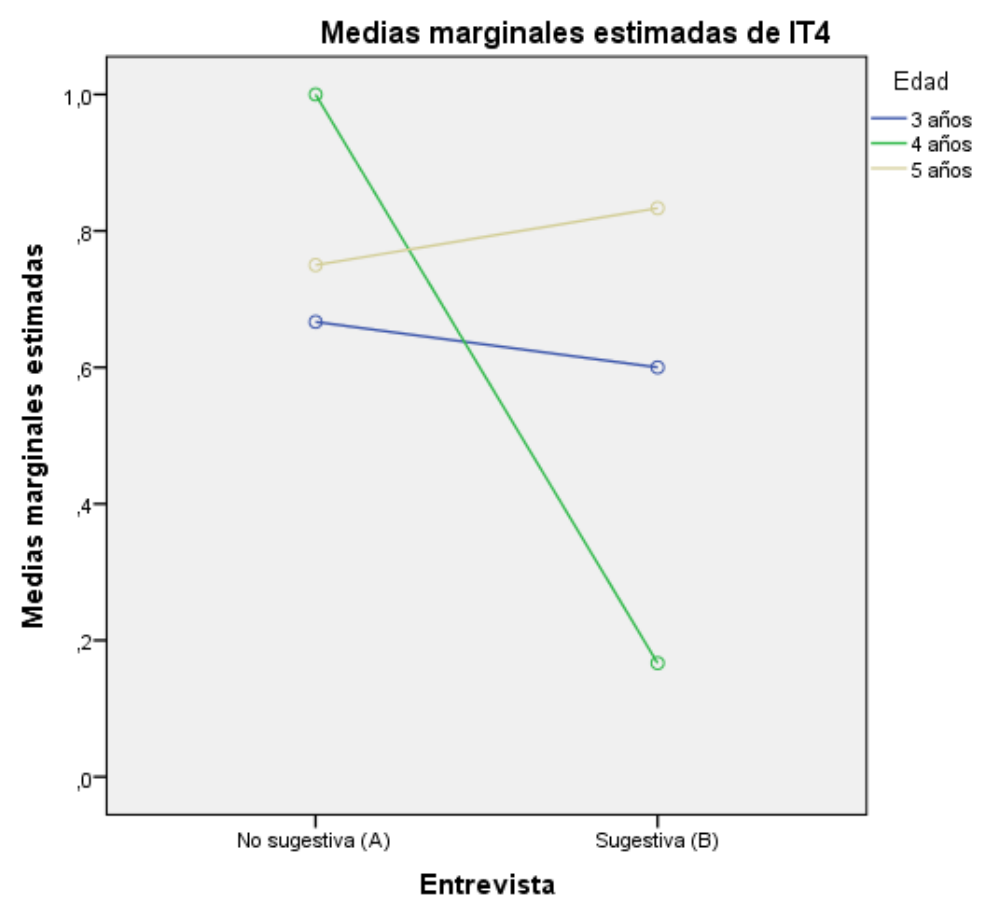




\section{Apéndice J}

\section{Análisis Ítem 5 por Entrevista y por Edad}

Pruebas de efectos inter-sujetos

Variable dependiente: IT5

\begin{tabular}{|c|c|c|c|c|c|}
\hline Origen & $\begin{array}{l}\text { Tipo III de } \\
\text { suma de } \\
\text { cuadrados }\end{array}$ & gl & $\begin{array}{c}\text { Cuadrático } \\
\text { promedio }\end{array}$ & $\mathrm{F}$ & Sig. \\
\hline $\begin{array}{l}\text { Modelo } \\
\text { corregido }\end{array}$ &, $658^{\mathrm{a}}$ & 5 & ,132 &, 551 &, 736 \\
\hline Interceptación & 2,546 & 1 & 2,546 & 10,658 &, 004 \\
\hline Entrevista & ,425 & 1 & ,425 & 1,778 & , 199 \\
\hline Edad & ,241 & 2 &, 120 &, 504 & ,612 \\
\hline $\begin{array}{l}\text { Entrevista } \\
\text { Edad }\end{array}$ & ,432 & 2 & ,216 & ,904 & ,422 \\
\hline Error & 4,300 & 18 & ,239 & & \\
\hline Total & 7,000 & 24 & & & \\
\hline Total corregido & 4,958 & 23 & & & \\
\hline
\end{tabular}

\section{Gráficos de perfil}

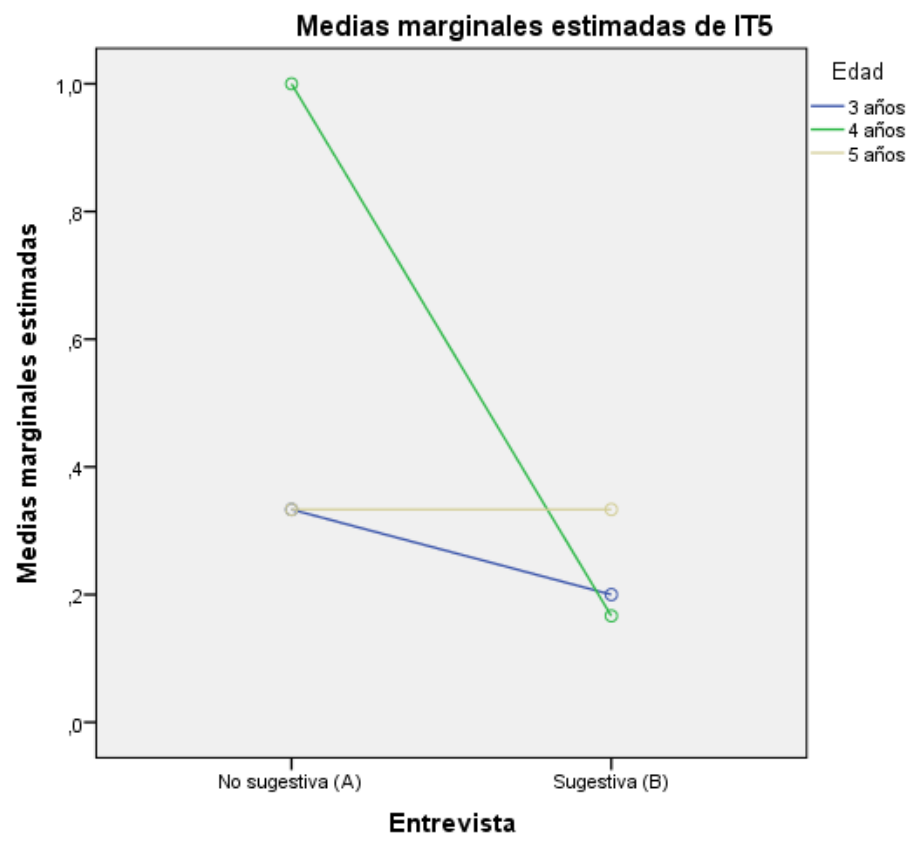




\section{Apéndice K}

\section{Análisis Ítem 6 por Entrevista y por Edad}

\section{Pruebas de efectos inter-sujetos}

Variable dependiente: IT6

\begin{tabular}{|c|c|c|c|c|c|}
\hline Origen & $\begin{array}{l}\text { Tipo III de } \\
\text { suma de } \\
\text { cuadrados }\end{array}$ & gl & $\begin{array}{l}\text { Cuadrático } \\
\text { promedio }\end{array}$ & $\mathrm{F}$ & Sig. \\
\hline $\begin{array}{l}\text { Modelo } \\
\text { corregido }\end{array}$ & $1,855^{\mathrm{a}}$ & 5 & 371 & 2,144 & , 124 \\
\hline Interceptación & 3,169 & 1 & 3,169 & 18,310 & 001 \\
\hline Entrevista &, 280 & 1 & ,280 & 1,618 & 226 \\
\hline Edad & 1,278 & 2 & ,639 & 3,693 &, 054 \\
\hline $\begin{array}{l}\text { Entrevista * } \\
\text { Edad }\end{array}$ & ,744 & 2 & ,372 & 2,149 & 156 \\
\hline Error & 2,250 & 13 & ,173 & & \\
\hline Total & 6,000 & 19 & & & \\
\hline Total corregido & 4,105 & 18 & & & \\
\hline
\end{tabular}

\section{Gráficos de perfil}

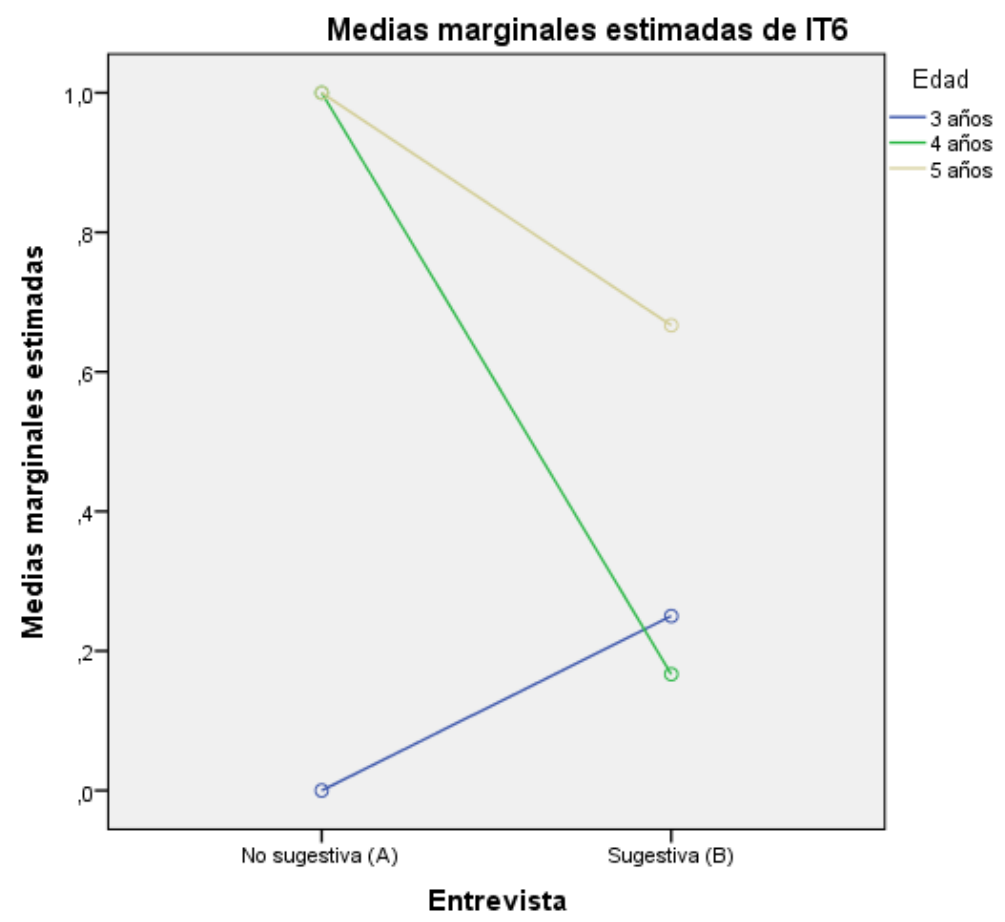




\section{Apéndice L}

\section{Análisis Ítem 7 por Entrevista y por Edad}

Variable dependiente: IT7

\section{Pruebas de efectos inter-sujetos}

\begin{tabular}{|c|c|c|c|c|c|}
\hline Origen & $\begin{array}{l}\text { Tipo III de } \\
\text { suma de } \\
\text { cuadrados }\end{array}$ & gl & $\begin{array}{l}\text { Cuadrático } \\
\text { promedio }\end{array}$ & $\mathrm{F}$ & Sig. \\
\hline $\begin{array}{l}\text { Modelo } \\
\text { corregido }\end{array}$ & $3,208^{\mathrm{a}}$ & 5 & ,642 & 4,779 &, 006 \\
\hline Interceptación & 8,374 & 1 & 8,374 & 62,373 &, 000 \\
\hline Entrevista & 2,396 & 1 & 2,396 & 17,845 &, 001 \\
\hline Edad &, 303 & 2 &, 151 & 1,127 & ,346 \\
\hline $\begin{array}{l}\text { Entrevista * } \\
\text { Edad }\end{array}$ & ,388 & 2 & 194 & 1,446 & ,262 \\
\hline Error & 2,417 & 18 & ,134 & & \\
\hline Total & 15,000 & 24 & & & \\
\hline Total corregido & 5,625 & 23 & & & \\
\hline
\end{tabular}

\section{Gráficos de perfil}

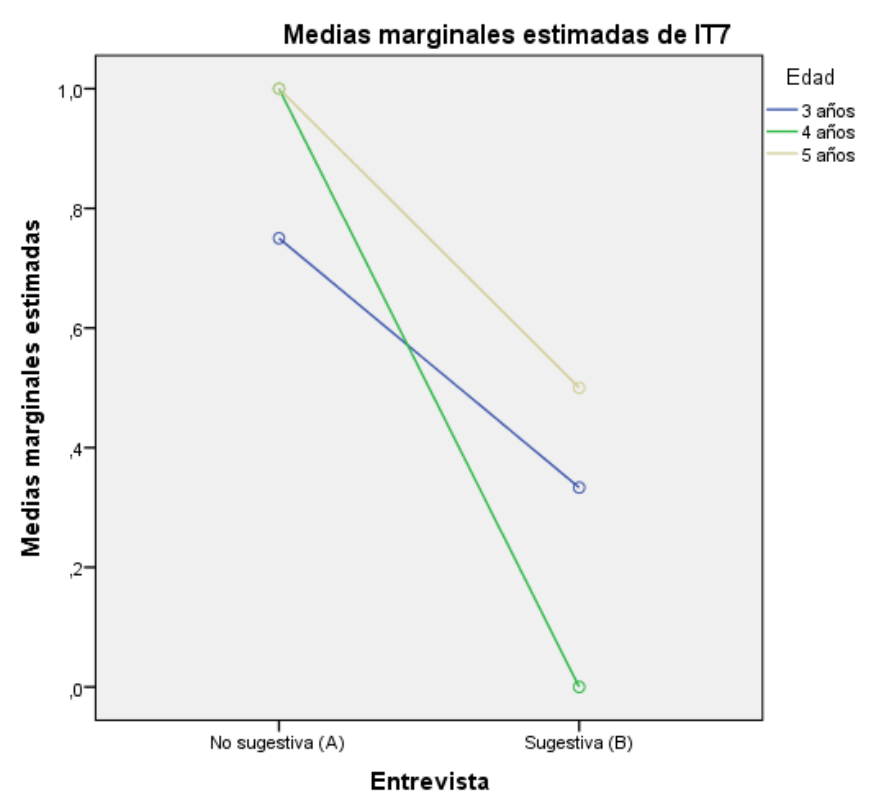




\section{Apéndice M}

\section{Análisis Ítem 8 por Entrevista y por Edad}

Variable dependiente: IT8

\section{Pruebas de efectos inter-sujetos}

Tipo III de

suma de

\begin{tabular}{|c|c|c|c|c|c|}
\hline Origen & cuadrados & gl & promedio & $\mathrm{F}$ & Sig. \\
\hline $\begin{array}{l}\text { Modelo } \\
\text { corregido }\end{array}$ & $1,161^{\mathrm{a}}$ & 5 & ,232 & ,891 & ,502 \\
\hline Interceptación & 9,296 & 1 & 9,296 & 35,662 &, 000 \\
\hline Entrevista & ,028 & 1 & ,028 & ,109 &, 744 \\
\hline Edad & ,861 & 2 & ,431 & 1,652 & ,212 \\
\hline $\begin{array}{l}\text { Entrevista * } \\
\text { Edad }\end{array}$ & ,174 & 2 & ,087 & ,334 & ,719 \\
\hline Error & 6,517 & 25 & ,261 & & \\
\hline Total & 17,000 & 31 & & & \\
\hline Total corregido & 7,677 & 30 & & & \\
\hline
\end{tabular}

\section{Gráficos de perfil}

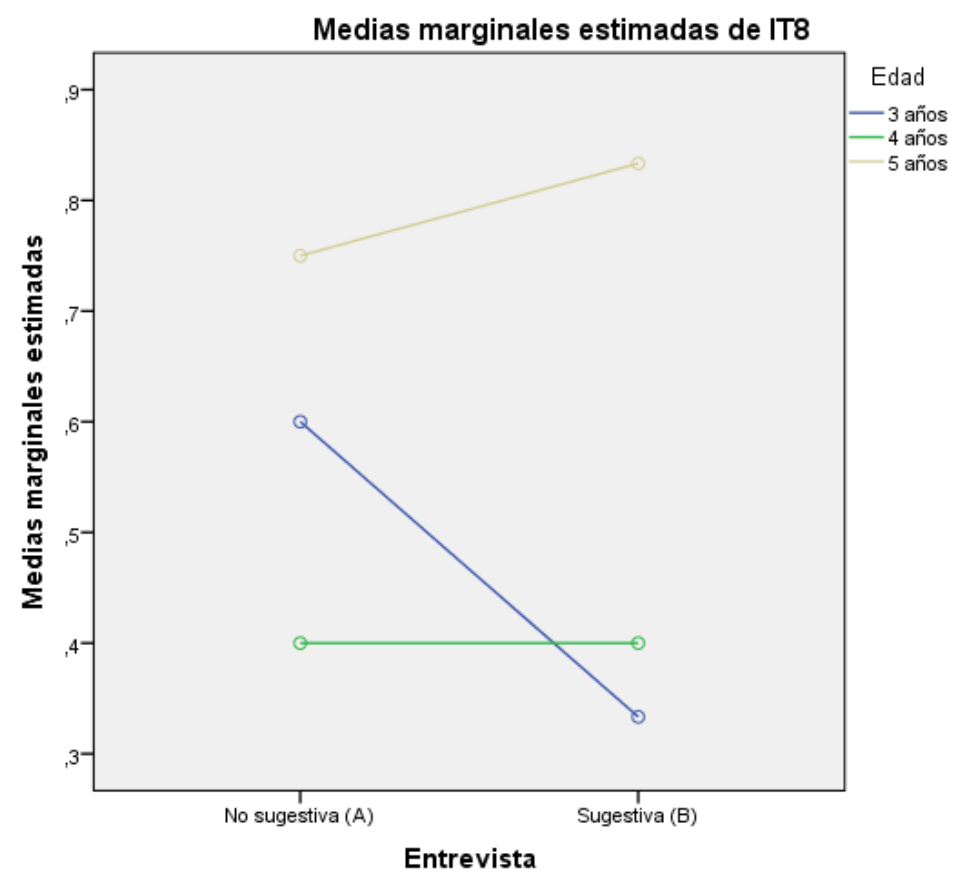




\section{Apéndice N}

\section{Análisis Ítem 9 por Entrevista y por Edad}

Pruebas de efectos inter-sujetos

Variable dependiente: IT9

\begin{tabular}{|c|c|c|c|c|c|}
\hline Origen & $\begin{array}{l}\text { Tipo III de } \\
\text { suma de } \\
\text { cuadrados }\end{array}$ & $\mathrm{gl}$ & $\begin{array}{c}\text { Cuadrático } \\
\text { promedio }\end{array}$ & $\mathrm{F}$ & Sig. \\
\hline $\begin{array}{l}\text { Modelo } \\
\text { corregido }\end{array}$ & $2,500^{\mathrm{a}}$ & 5 & ,500 & 2,500 & ,065 \\
\hline Interceptación & 6,353 & 1 & 6,353 & 31,765 & ,000 \\
\hline Entrevista & 1,588 & 1 & 1,588 & 7,941 & ,011 \\
\hline Edad & 1,094 & 2 & ,547 & 2,734 & ,089 \\
\hline $\begin{array}{l}\text { Entrevista * } \\
\text { Edad }\end{array}$ & ,000 & 2 & ,000 & ,000 & 1,000 \\
\hline Error & 4,000 & 20 & 200 & & \\
\hline Total & 13,000 & 26 & & & \\
\hline Total corregido & 6,500 & 25 & & & \\
\hline
\end{tabular}

\section{Gráficos de perfil}

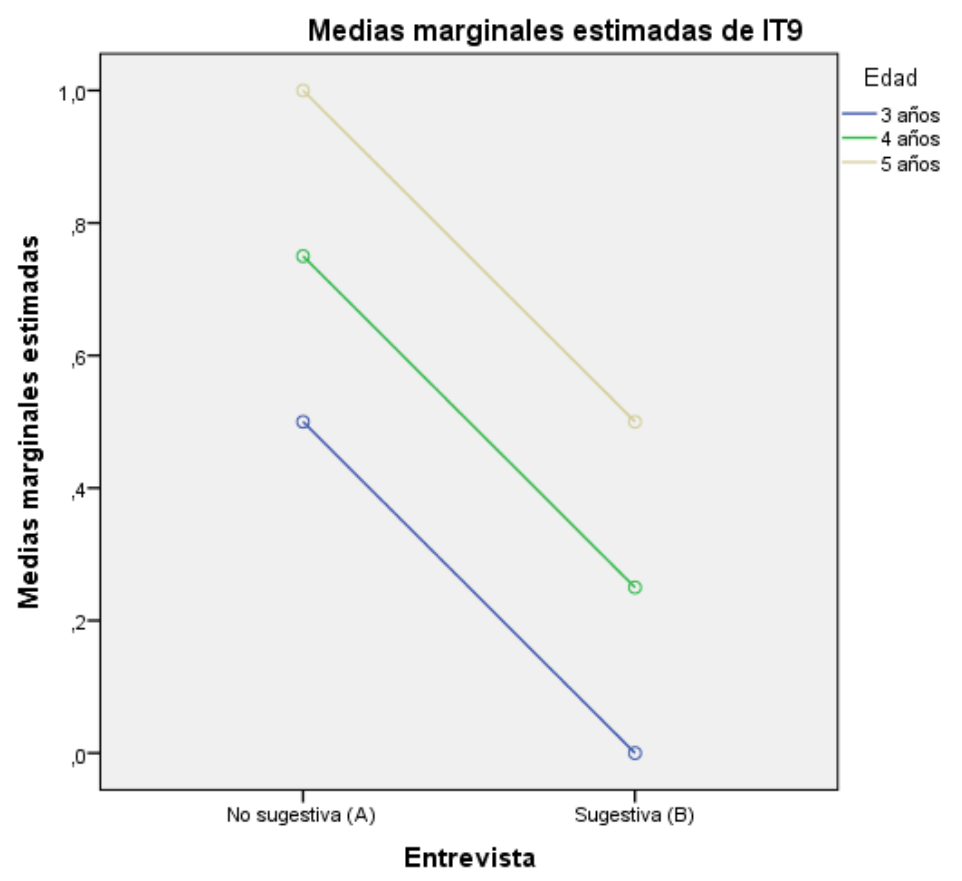

